\title{
The Atypical Chemokine Receptor 2 Limits Progressive Fibrosis after Acute Ischemic Kidney Injury
}

\author{
Moritz Lux, ${ }^{*}$ Alexander Blaut, ${ }^{*}$ Nuru Eltrich, ${ }^{*}$ Andrei Bideak, ${ }^{*}$ Martin B. Müller, ${ }^{*}$ John M. Hoppe, ${ }^{*}$ Hermann-Josef Gröne,
} Massimo Locati, ${ }^{\ddagger \S}$ and Volker Vielhauer*

From the Division of Nephrology, ${ }^{*}$ Department of Medicine IV, University Hospital, Ludwig-Maximilians-Universität München, Munich, Germany; the Department of Cellular and Molecular Pathology, ${ }^{\dagger}$ German Cancer Research Center, Heidelberg, Germany; the Humanitas Clinical and Research Center, ${ }^{\ddagger}$ Rozzano, Italy; and the Department of Medical Biotechnologies and Translational Medicine, ${ }^{\S}$ Università degli Studi di Milano, Milan, Italy

\author{
Accepted for publication \\ September 27, 2018. \\ Address correspondence to \\ Volker Vielhauer, M.D., \\ Division of Nephrology, \\ Department of Medicine IV, \\ University Hospital, Ludwig- \\ Maximilians-Universität \\ München, Ziemssenstrasse 1, \\ 80336 Munich, Germany. E- \\ mail: volker.vielhauer@med.uni- \\ muenchen.de.
}

\begin{abstract}
Following renal ischemia-reperfusion injury (IRI), resolution of inflammation allows tubular regeneration, whereas ongoing inflammatory injury mediated by infiltrating leukocytes leads to nephron loss and renal fibrosis, typical hallmarks of chronic kidney disease. Atypical chemokine receptor 2 (ACKR2) is a chemokine decoy receptor that binds and scavenges inflammatory $\mathrm{CC}$ chemokines and reduces local leukocyte accumulation. We hypothesized that ACKR2 limits leukocyte infiltration, inflammation, and fibrotic tissue remodeling after renal IRI, thus preventing progression to chronic kidney disease. Compared with wild type, Ackr2 deficiency increases CC chemokine ligand 2 levels in tumor necrosis factor-stimulated tubulointerstitial tissue in vitro. In Ackr2-deficient mice with early IRI 1 or 5 days after transient renal pedicle clamping, tubular injury was similar to wild type, although accumulation of mononuclear phagocytes increased in postischemic $A c \mathrm{kr}^{-/-}$kidneys. Regarding long-term outcomes, $A c \mathrm{kr}^{-/-}$kidneys displayed more tubular injury 5 weeks after IRI, which was associated with persistently increased renal infiltrates of mononuclear phagocytes, T cells, Ly6C ${ }^{\text {high }}$ inflammatory macrophages, and inflammation. Moreover, Ackr2 deficiency caused substantially aggravated renal fibrosis in $A c k 2^{-1-}$ kidneys 5 weeks after IRI, shown by increased expression of matrix molecules, renal accumulation of $\alpha$-smooth muscle actin-positive myofibroblasts, and bone marrow-derived fibrocytes. ACKR2 is important in limiting persistent inflammation, tubular loss, and renal fibrosis after ischemic acute kidney injury and, thus, can prevent progression to chronic renal disease. (Am J Pathol 2019, 189: 231-247; https://doi.org/10.1016/j.ajpath.2018.09.016)
\end{abstract}

Acute kidney injury (AKI) is a risk factor for the development of chronic kidney disease (CKD) later in life. ${ }^{1}$ Loss of nephrons due to insufficient repair and fibrotic tissue remodeling underlies the progression from acute to chronic renal injury. After the extent of initial injury, the associated inflammatory response represents a determinant of AKI outcome. ${ }^{2}$ In ischemia-reperfusion injury (IRI), a major cause for human AKI, the release of danger-associated molecular patterns, proinflammatory cytokines, and chemokines by the injured tubules triggers an influx of leukocytes into the site of injury, which further mediates tubular damage. ${ }^{2-4}$ In addition, ongoing inflammation increases and activates fibrogenic cells in the renal interstitium, including phagocytes, fibroblasts, and myofibroblasts. ${ }^{4-6}$ Excessive production of extracellular matrix by these cells drives fibrotic remodeling, which not only replaces irreversibly damaged nephrons but may directly contribute to progressive tubular injury by compromising capillary

Supported by Deutsche Forschungsgemeinschaft DFG grant VI 231/3-1 (V.V.) and Faculty of Medicine, LMU Munich grants FöFoLe 26/2012 and 09/2014 (V.V., M.L., and A.B1.).

Disclosures: None declared.

Portions of this work were presented at The American Society of Nephrology, Kidney Week 2017, held October 31 to November 5, 2017, in New Orleans, LA, and prepared by M.L. as part of his doctoral thesis at the Faculty of Medicine, LMU Munich. 
blood flow and diffusion of oxygen and nutrients. Therefore, limiting renal inflammation after AKI is crucial to prevent ongoing tubular injury and renal fibrosis (ie, the progression from AKI to CKD). ${ }^{2}$

The atypical chemokine receptor 2 (ACKR2), previously called D6, is a chemokine scavenging receptor that belongs to the subfamily of atypical chemokine receptors. ACKR2 binds with high affinity to proinflammatory $\mathrm{CC}$ chemokines and fosters to their intracellular degradation, thereby reducing local chemokine levels. ${ }^{7}$ By scavenging chemokines in tissue, ACKR2 plays important roles in limiting local inflammatory responses, in the resolution of inflammation, and in the regulation of adaptive immune responses. ${ }^{7,8}$ ACKR2 is present in many parenchymal organs, including barrier tissues like the skin, gut, lung, and placenta, ${ }^{9,10}$ with the major site of ACRK2 expression being on lymphatic endothelial cells. ${ }^{11}$ Analysis of Ackr2-deficient mice demonstrated that ACKR2 limits inflammatory responses and tissue injury in several disease models, including skin inflammation, myocardial infarction, systemic infection with Mycobacterium tuberculosis, and toxic liver injury. ${ }^{12-15}$ Moreover, ACKR2 deficiency on lymphatic endothelium leads to accumulation of inflammatory chemokines and inappropriate clustering of inflammatory leukocytes around lymphatic capillaries, which reduces fluid flow and dendritic cell entry into lymphatics and regional lymph nodes. ${ }^{16,17}$ Thus, impaired lymphatic drainage of inflammatory cells, chemokines, and cytokines may contribute to exaggerated inflammation in $A c k r 2$-deficient tissues and may also explain the reduced T-cell priming seen in some disease models. ${ }^{18,19}$

By limiting and resolving inflammatory responses, ACKR2 activity may also be an important determinant of recovery versus subsequent progressive CKD after AKI. Herein, we speculated that ACKR2 reduces renal inflammation and fibrotic remodeling after AKI, which are typical hallmarks of developing CKD. Ackr2-deficient mice subjected to renal IRI with extended follow-up and aristolochic acid-induced nephropathy were analyzed as models for acute to chronic kidney injury to explore this concept.

\section{Materials and Methods}

\section{Mice}

Ackr2-deficient mice $\left(A c k r 2^{-1-}\right.$ ) on the C57BL/6J background have been previously described. ${ }^{14,20}$ All experiments were performed on 7- to 10-week-old $A c k r 2^{-/-}$mice with wildtype littermate controls. All experimental procedures were conducted according to the German animal care and ethics legislation and approved by local government authorities.

\section{Induction of Renal Ischemia-Reperfusion Injury}

Age-matched groups of female mice were anesthetized before both renal pedicles (acute IRI model) or only the left renal pedicle (subacute and chronic IRI model) was clamped for 25 or 45 minutes, respectively, with a microaneurysm clamp (Medicon, Tuttlingen, Germany) via flank incisions. Body temperature was maintained at $37^{\circ} \mathrm{C}$ throughout the procedure by placing mice on a heat pad. After clamp removal, restoration of renal blood flow was confirmed by reappearance of original color, and wounds were closed with standard sutures. Mice were euthanized 1, 5, or 35 days after renal pedicle clamping. Phosphate-buffered saline-perfused kidney tissue was stored for further analysis. Serum values for creatinine and urea were measured with an Olympus AU640 auto-analyzer at Synlab.vet (Augsburg, Germany).

\section{Obstructive Nephropathy after UUO}

Obstructive nephropathy was induced in age-matched groups of female mice by unilateral ureteral ligation, as described previously. ${ }^{21,22}$ Unobstructed contralateral kidneys served as controls. At day 7 or 14 after unilateral ureteral obstruction (UUO), the mice were euthanized, and tissue of perfused obstructed and contralateral kidneys was stored for further analysis.

\section{Aristolochic Acid-Induced Nephropathy}

Aristolochic acid-induced nephropathy was induced in 9week-old male mice by i.p. injection of aristolochic acid I sodium salt (Sigma-Aldrich, Deisenhofen, Germany). ${ }^{23}$ Five injections of $5 \mathrm{mg} / \mathrm{kg}$ every second day resulted in tubular injury and subsequent development of chronic renal failure and fibrosis. At day 14, mice were euthanized for analysis of renal pathology.

\section{RNA in Situ Hybridization for Ackr2}

Paraffin sections ( $5 \mu \mathrm{m}$ thick) were baked in a dry oven at $60^{\circ} \mathrm{C}$ for 1 hour before RNAscope assay application (Advanced Cell Diagnostic, Hayward, CA). The probe for murine Ackr2 mRNA was developed by Advanced Cell Diagnostic. Ackr2 mRNA was localized using the RNAscope $2.5 \mathrm{HD}$ reagent kit RED (Advanced Cell Diagnostic) as a detection reagent.

\section{Assessment of Renal Injury by Histology and Immunohistochemistry}

Renal tissue was embedded in paraffin, and sections $(2 \mu \mathrm{m}$ thick) were used for periodic acid-Schiff and Masson trichrome staining or immunohistochemistry following standard protocols. The extent of tubular injury was determined on periodic acid-Schiff-stained sections by additive scoring of four damage markers of tubules in the corticomedullary junction (ie, tubular dilation, denudation, intraluminal casts, and cell flattening), each in a range of 0 to $3 .{ }^{24}$ Interstitial volume expansion was semiquantitatively assessed, as described. ${ }^{21}$ The extent of postischemic tubular loss was quantified by staining for Lotus tetragonolobus lectin to identify proximal tubules with ImageJ software version 
Table 1 Primers Used for Real-Time RT-qPCR

\begin{tabular}{|c|c|}
\hline Primer name & Primer sequence \\
\hline \multirow[t]{2}{*}{ ACKR2 } & F: 5'-СТTCTTTTAСTCCCGCATCG-3' \\
\hline & R: 5'-TATGGGAACCACAGCATGAA-3' \\
\hline \multirow[t]{2}{*}{ CCL2 } & F: 5'-CCTGCTGTTCACAGTTGCC-3' \\
\hline & R: 5'-ATTGGGATCATCTTGCTGGT-3' \\
\hline \multirow[t]{2}{*}{ CCL5 } & F: 5'-ССАСТTСTTCTCTGGGTTGG-3' \\
\hline & R: 5'-GTGCCCACGTCAAGGAGTAT-3' \\
\hline \multirow[t]{2}{*}{ CCL22 } & F: 5'-TCTGGACCTCAAAATCCTGC-3' \\
\hline & R: 5'-TGGAGTAGCTTCTTCACCCA-3' \\
\hline \multirow[t]{2}{*}{ CXCL10 } & F: 5'-GGCTGGTCACCTTTCAGAAG-3' \\
\hline & R: $5^{\prime}-$ ATGGATGGACAGCAGAGAGC $-3^{\prime}$ \\
\hline \multirow[t]{2}{*}{ TNF- $\alpha$} & F: 5'-CCACCACGCTCTTCTGTCTAC-3' \\
\hline & R: $5^{\prime}$-AGGGTCTGGGCCATAGAACT-3' \\
\hline \multirow[t]{2}{*}{ IL-6 } & F: 5'-TGATGCACTTGCAGAAAACA-3' \\
\hline & R: $5^{\prime}$-ACCAGAGGAAATTTTCAATAGGC- $3^{\prime}$ \\
\hline \multirow[t]{2}{*}{ IL-10 } & F: 5'-ATCGATTTCTCCCCTGTGAA-3' \\
\hline & R: 5'-TGTCAAATTCATTCATGGCCT-3' \\
\hline \multirow[t]{2}{*}{$\mathrm{IL}-12 \beta$} & F: 5'-GATTCAGACTCCAGGGGACA-3' \\
\hline & R: 5'-GGAGACACCAGCAAAACGAT-3' \\
\hline \multirow[t]{2}{*}{ IFN- $\gamma$} & F: 5'-ACAGCAAGGCGAAAAAGGAT- 3' \\
\hline & R: 5'-TGAGCTCATTGAATGCTTGG-3' \\
\hline \multirow[t]{2}{*}{ iNOS1 } & F: 5'-TTCTGTGCTGTCCCAGTGAG-3' \\
\hline & R: 5'-TGAAGAAAACCCCTTGTGCT-3' \\
\hline \multirow[t]{2}{*}{ CTGF } & F: 5'-AGCTGACCTGGAGGAAAACA-3' \\
\hline & R: 5'-CCGCAGAACTTAGCCCTGTA-3' \\
\hline \multirow[t]{2}{*}{ MRC1 } & F: 5'-ATATATAAACAAGAATGGTGGGCAGT-3' \\
\hline & R: 5'-TССАТССАААТGААТTTСТTАТСС-3' \\
\hline \multirow[t]{2}{*}{ MSR-1 } & F: 5'-CCTCCGTTCAGGAGAAGTTG-3' \\
\hline & R: 5'-TTTCССААТTСАААAGCTGA-3' \\
\hline \multirow[t]{2}{*}{ Arg1 } & F: 5'-AGAGATTATCGGAGCGCCTT-3' \\
\hline & R: 5'-TTTTTCCAGCAGACCAGCTT-3' \\
\hline \multirow[t]{2}{*}{ FIZZ-1 } & F: 5'-СССТTСТСАТСТGСАТСТCC-3' \\
\hline & R: 5'-CTGGATTGGCAAGAAGTTCC-3' \\
\hline \multirow[t]{2}{*}{ Fibronectin } & F: 5'-GGAGTGGCACTGTCAACCTC-3' \\
\hline & R: $5^{\prime}-$ ACTGGATGGGGTGGGAAT-3' \\
\hline \multirow[t]{2}{*}{ Laminin } & F: 5'-CATGTGCTGCCTAAGGATGA-3' \\
\hline & R: 5'-TCAGCTTGTAGGAGATGCCA-3' \\
\hline \multirow[t]{2}{*}{ Collagen $1 \propto 1$} & F: 5'-ACATGTTCAGCTTTGTGGACC-3' \\
\hline & R: 5'-TAGGCCATTGTGTATGCAGC-3' \\
\hline \multirow[t]{2}{*}{ Collagen $4 \alpha 1$} & F: 5'-GTCTGGCTTCTGCTGCTCTT-3' \\
\hline & R: 5'-CACATTTTCCACAGCCAGAG-3' \\
\hline \multirow[t]{2}{*}{$\alpha-S M A$} & F: 5'-ACTGGGACGACATGGAAAAG-3' \\
\hline & R: 5'-GTTCAGTGGTGCCTCTGTCA-3' \\
\hline \multirow[t]{2}{*}{ FSP1 } & F: 5'-CAGCACTTCСTCTCTCTTGG-3' \\
\hline & R: 5'-TTTGTGGAAGGTGGACACAA-3' \\
\hline
\end{tabular}

Arg, arginase; $\mathrm{CCL}$, chemokine (C-C motif) ligand; CTGF, connective tissue growth factor; $\mathrm{F}$, forward; FIZZ-1, a resistin-like protein markedly induced by IL-4 and IL-13; FSP; fibroblast-specific protein; IFN, interferon; iNOS, inducible nitric oxide synthase; MRC, mannose receptor; MSR, macrophage scavenger receptor; $R$, reverse; RT-qPCR, real-time quantitative RT-PCR; SMA; smooth muscle actin; TNF, tumor necrosis factor.

1.51p (NIH, Bethesda, MD; https://imagej.nih.gov/ij) in five low-power fields per kidney (original magnification, $\times 200$ ). Tubular injury and interstitial volume expansion in obstructed kidneys after UUO were scored semiquantitatively, as described. ${ }^{21}$ The extent of interstitial fibrosis was quantified by assessing the fraction of collagen- rich fibrotic matrix visualized by Masson trichrome staining in 10 low-power fields per kidney with ImageJ software. Myofibroblasts were assessed by quantifying the fraction of stained area for $\alpha$-smooth muscle actin ( $\alpha$-SMA; 1:300, clone 1A4; Dako Agilent, Santa Clara, CA) in five to eight cortical low-power fields per kidney.

For evaluation of renal leukocyte infiltrates by immunohistochemistry, paraffin-embedded renal sections were stained with antibodies against neutrophils (Ly-6B.2, clone 7/4, 1:50; Abd Serotec, Oxford, UK), mononuclear phagocytes (F4/80, clone Cl:A3-1, 1:100; Abd Serotec), and $\mathrm{CD}^{+} \mathrm{T}$ cells $(\mathrm{CD} 3$, 1:100, clone CD3-12; Abd Serotec), as previously described. ${ }^{22}$ Stained cells were counted in 8 to 10 cortical high-power fields per kidney. F4/80-positive tubulointerstitial infiltrates were quantified as fraction of stained area using ImageJ software. All assessments were performed in a blinded protocol (M.L., A.Bl., and V.V.).

\section{Flow Cytometry of Leukocytes in Kidneys, Peripheral Blood, Spleen, and Bone Marrow}

Preparation of renal single-cell suspensions and antibody staining were performed as previously described. ${ }^{22,25}$ Leukocyte subsets were quantified by four-color flow cytometry using fluorochrome-conjugated antibodies directed to CD45 (clone 30-F11), CD11b (M1/70), CD11c (HL3), Ly-6G (1A8), Ly-6C (AL-21), CD3e (145-2C11), CD4 (RM4-5), CD8 (53-6.7; all from BD Biosciences, Heidelberg, Germany), F4/80 (clone CL:A3-1; Abd Serotec), and rat anti-CCR2 (clone 475301; R\&D Systems, Abingdon, UK). Lymphocytes, monocytes, and granulocytes in peripheral blood were identified by light scatter properties. Intrarenal fibrocytes were identified by surface staining for CD45 and CD11b, followed by intracellular staining with biotinylated anticollagen 1 or respective isotype control (Rockland Immunochemicals, Gilbertsville, PA), as published. ${ }^{26}$ Analysis was performed with a FACSCalibur flow cytometer and Cellquest Pro software version 6.0 (BD Biosciences). The number of stained renal leukocytes was expressed as percentage of total renal cells. Peripheral blood leukocytes, total leukocytes per spleen, and bone marrow prepared from the right femur were quantified by adding counting beads (Molecular Probes, Eugene, OR).

\section{Quantitative RT-PCR}

Total RNA was extracted from whole kidneys using the Purelink RNA Mini Kit (Invitrogen, Carlsbad, CA). SYBR Green master mix (Invitrogen) was used to perform realtime quantitative RT-PCR on a Light Cycler 480 (Roche, Mannheim, Germany). Gene-specific primers (300 nmol/L; Metabion, Martinsried, Germany) were used, as listed in Table 1. All samples were run in duplicate and normalized to $18 \mathrm{~S}$ rRNA. 

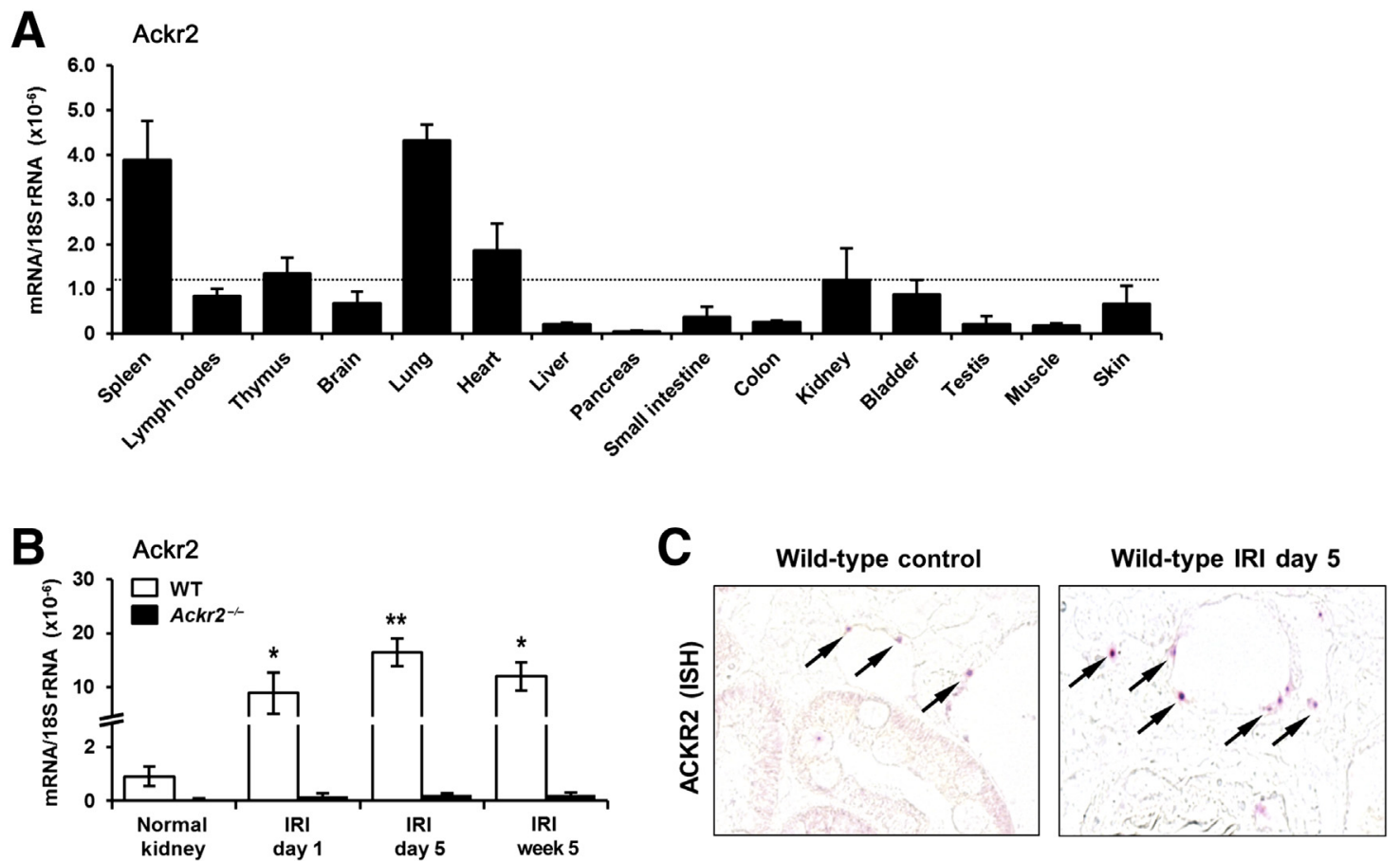

Figure 1 ACKR2 expression in mouse kidney. A: Analysis of Ackr2 mRNA expression in organs from seven adult male C57BL/6 mice reveals significant baseline Ackr2 mRNA levels in the kidney (dashed line), as well as spleen, lymph nodes, thymus, lung, heart, bladder, and skin. B: Renal Ackr2 mRNA expression is significantly induced in kidneys at 1 day, 5 days, and 5 weeks after ischemia-reperfusion injury (IRI) compared with healthy control kidneys, whereas no significant expression could be detected in Ackr2 ${ }^{-1-}$ mice. PCR results were normalized to 18S rRNA as a housekeeping gene. C: In situ hybridization (ISH) of Ackr2 demonstrates Ackr2 mRNA transcripts (red signals indicated by arrows) in interstitial lymphatic endothelial cells of wild-type (WT) control kidneys and more prominently in postischemic kidneys at day 5 after IRI. Images show representative cortical tissue. Data are expressed as mean \pm SEM. $n=5$ to 10 mice per group (B). ${ }^{*} P<0.05,{ }^{*} P<0.01$ compared with control kidney. Original magnification, $\times 400$ (C).

Analysis of KIM-1 and Chemokine Protein Levels by Enzyme-Linked Immunosorbent Assay

Renal kidney injury molecule (KIM)-1 expression and chemokine levels in kidney lysates and serum were measured using commercially available enzyme-linked immunosorbent assay kits for KIM-1, chemokine (C-C motif) ligand (CCL) 2, CCL5, and CXCL10 (R\&D Systems), following the manufacturer's protocols. Protein content of each kidney sample was determined using the Bradford assay. Chemokine protein levels were additionally normalized to the fraction of parenchymal tissue using the percentage of lectin-positive staining.

\section{Statistical Analysis}

Results are presented as means \pm SEM. Differences between two experimental groups were compared with a twotailed $t$-test, and $P<0.05$ was considered significant.

\section{Results}

Expression of ACKR2 in Healthy and Acutely Injured Murine Kidney

The expression of ACKR2 was first studied in different organs of healthy adult C57BL/6 mice. Significant Ackr2 mRNA baseline expression was present in kidney, with the most prominent expression seen in lung, spleen, and heart, whereas thymus, lymph nodes, bladder, and skin revealed similar expression levels as found in kidneys (Figure 1A). To further characterize the role of ACKR2 after AKI, Ackr2 mRNA expression was analyzed in kidneys at day 1 , at day 5 , and at 5 weeks after acute renal IRI. Compared with normal kidneys, Ackr2 mRNA levels were increased by 9.8-, 18.1-, and 13.2-fold, respectively, whereas no expression could be detected in $A c k r 2^{-1-}$ mice (Figure 1B). In control and ischemic kidneys, in situ hybridization analysis localized the expression of Ackr2 mRNA transcripts specifically to endothelial cells of the tubulointerstitium (Figure 1C), which were recently identified as LYVE-1-positive lymphatic endothelium. ${ }^{27}$ Consistently, increased CCL2 levels were demonstrated in supernatants of $A c k r 2$-deficient tubulointerstitial cells, but not glomeruli, compared with wild type on tumor necrosis factor- $\alpha$ stimulation in vitro. ${ }^{27}$ Similar to its reported function in skin, lung, and heart, ${ }^{12-14}$ these data suggest that renal ACKR2 expressed by tubulointerstitial lymphatic endothelial cells could scavenge chemokines produced in the tubulointerstitial compartment and, thus, may play an important role in limiting inflammatory responses after AKI.

\section{Ackr2 Deficiency Does Not Affect Early AKI after Bilateral IRI}

To explore the potential function of ACKR2 during the acute phase of renal injury, bilateral IRI was induced in 

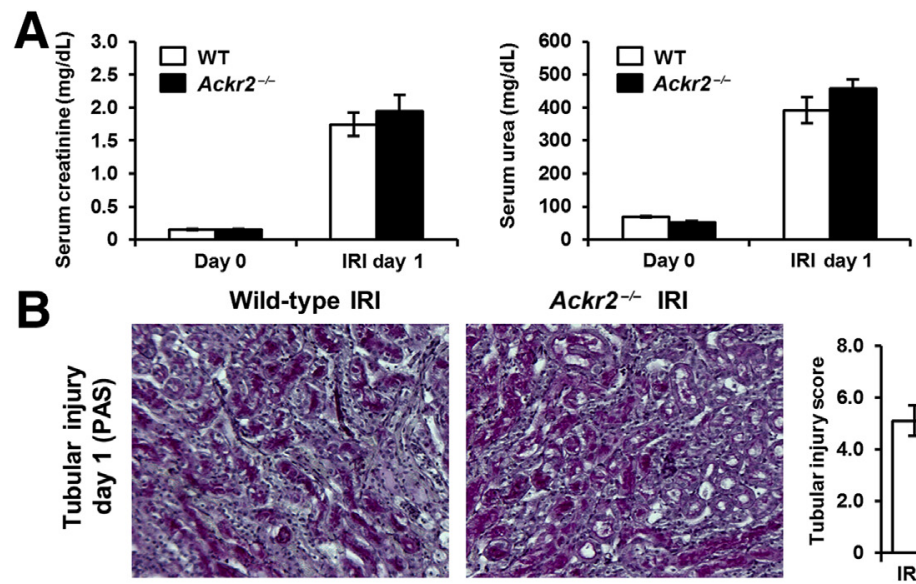

Ackr2-- IRI $^{-1}$
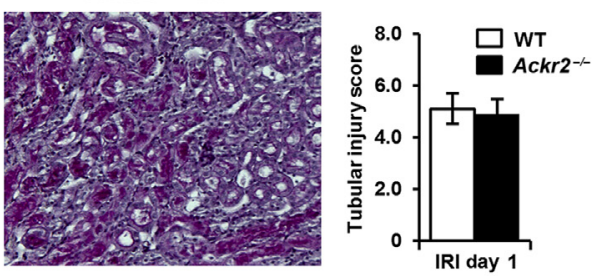

C
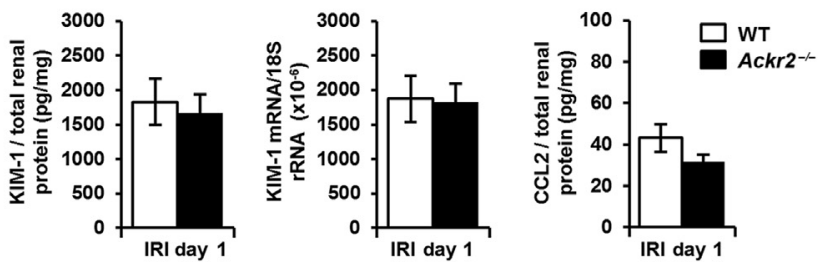

D
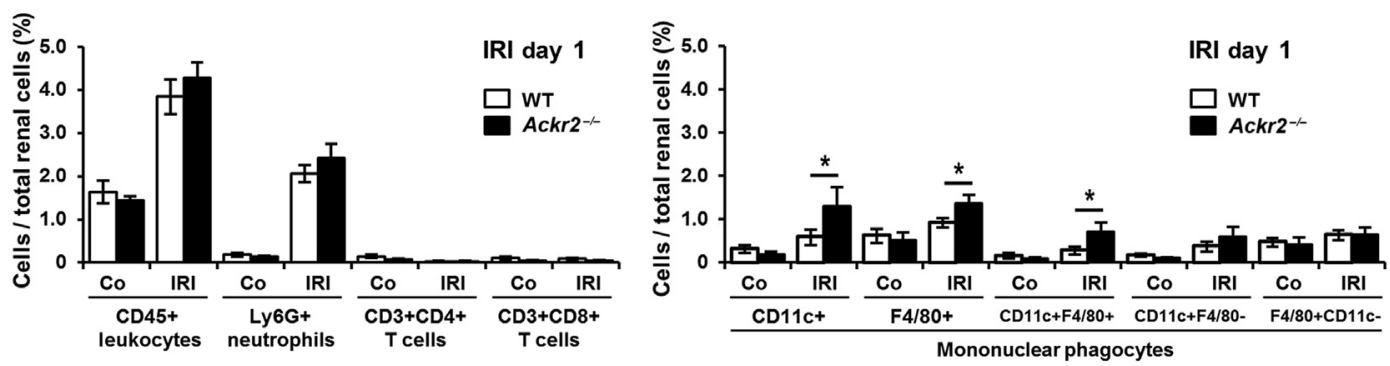

E

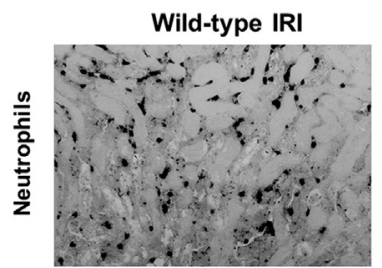

Ackr2 $^{-/}$IRI

Mononuclear phagocytes
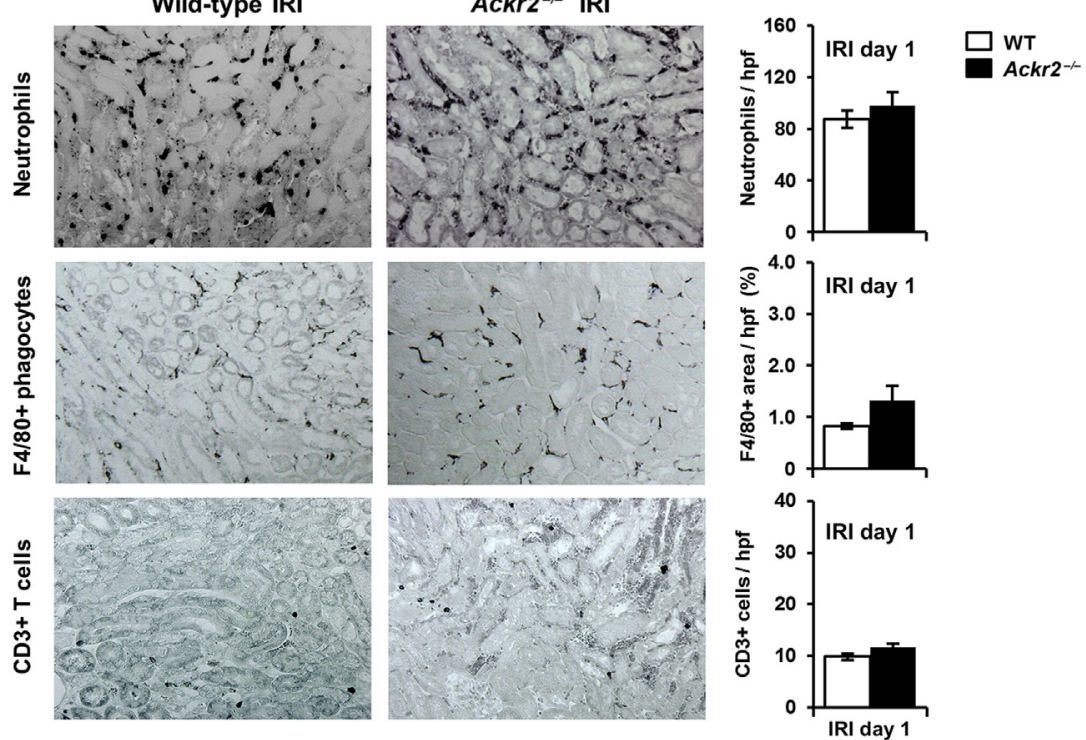

Figure 2 Ackr2 deficiency does not affect acute renal ischemia-reperfusion injury (IRI). Wild-type (WT) and $A c k r 2^{-/-}$mice underwent bilateral IRI for 30 minutes. A: Baseline levels and increases 24 hours after surgery of serum creatinine and urea are similar in both genotypes. B: Tubular injury, as evaluated by semiquantitative scoring of periodic acid-Schiff (PAS) -stained sections, is comparable at 24 hours after IRI in both groups of mice. C: Similarly, renal protein and mRNA expression levels of kidney injury molecule (KIM)-1 and renal chemokine (C-C motif) ligand (CCL) 2 levels are not different. D: Intrarenal leukocyte accumulation was analyzed by flow cytometry of renal single-cell suspensions prepared from age-matched uninjured control mice (Co) and mice 24 hours after IRI. Renal leukocyte content is similar in healthy kidneys, but significant increases of $\mathrm{CD} 11 \mathrm{c}^{+} \mathrm{F} 4 / 80^{+}$mononuclear phagocytes are present in ischemic $A c k 2^{-/-}$kidneys compared with WT kidneys. E: Representative renal sections of WT and Ackr2-deficient mice stained for Ly-6B. $2^{+}$neutrophils, $\mathrm{F} 4 / 80^{+}$interstitial mononuclear phagocytes, and $\mathrm{CD}^{+}{ }^{+} \mathrm{T}$ cells. Leukocyte infiltrates were quantified as described in Materials and Methods. A-E: Data are representative of two independently performed experiments. Data are expressed as means \pm SEM. $n=5$ to 6 mice per group $(\mathbf{A}-\mathbf{E}) .{ }^{*} P<0.05$. Original magnifications: $\times 200$ (B and $\mathbf{E}$, top and middle rows); $\times 400$ (E, bottom row). hpf, high-power field. 
A
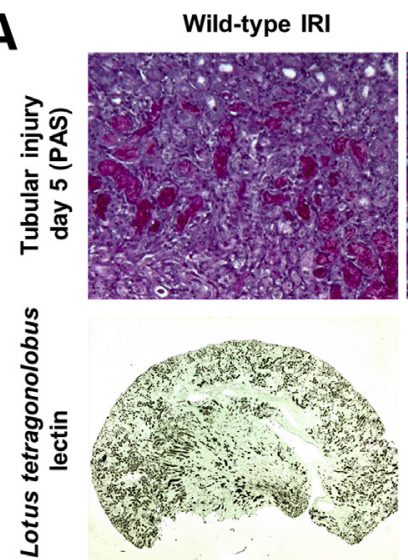

B

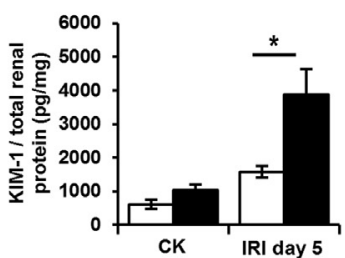

Ackr2 $^{-/}$IRI
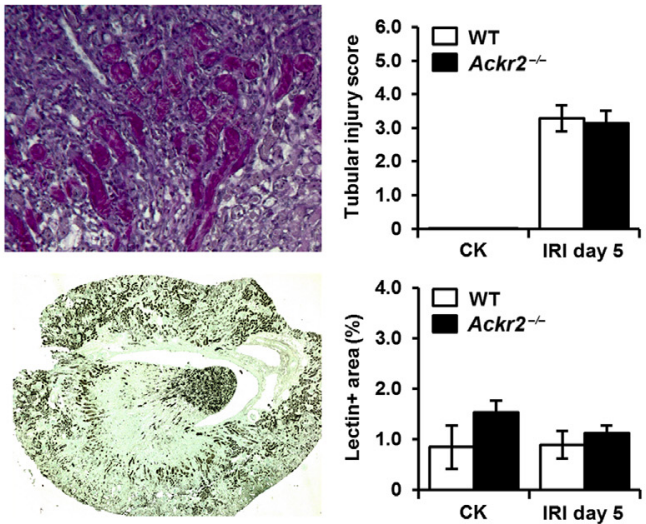
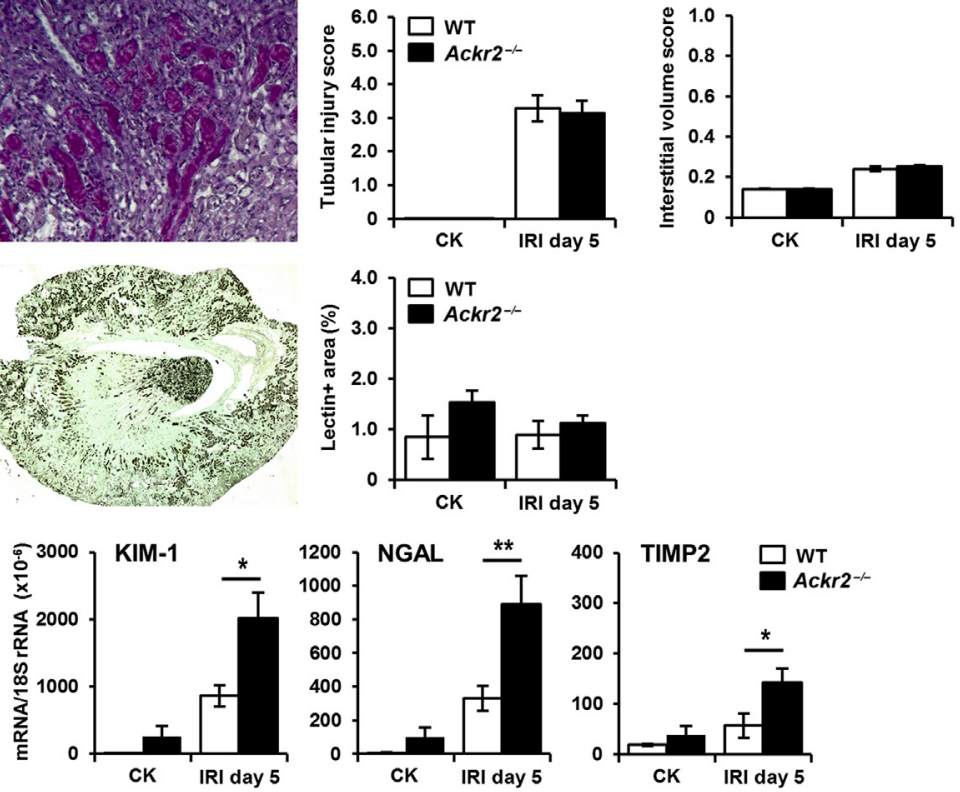
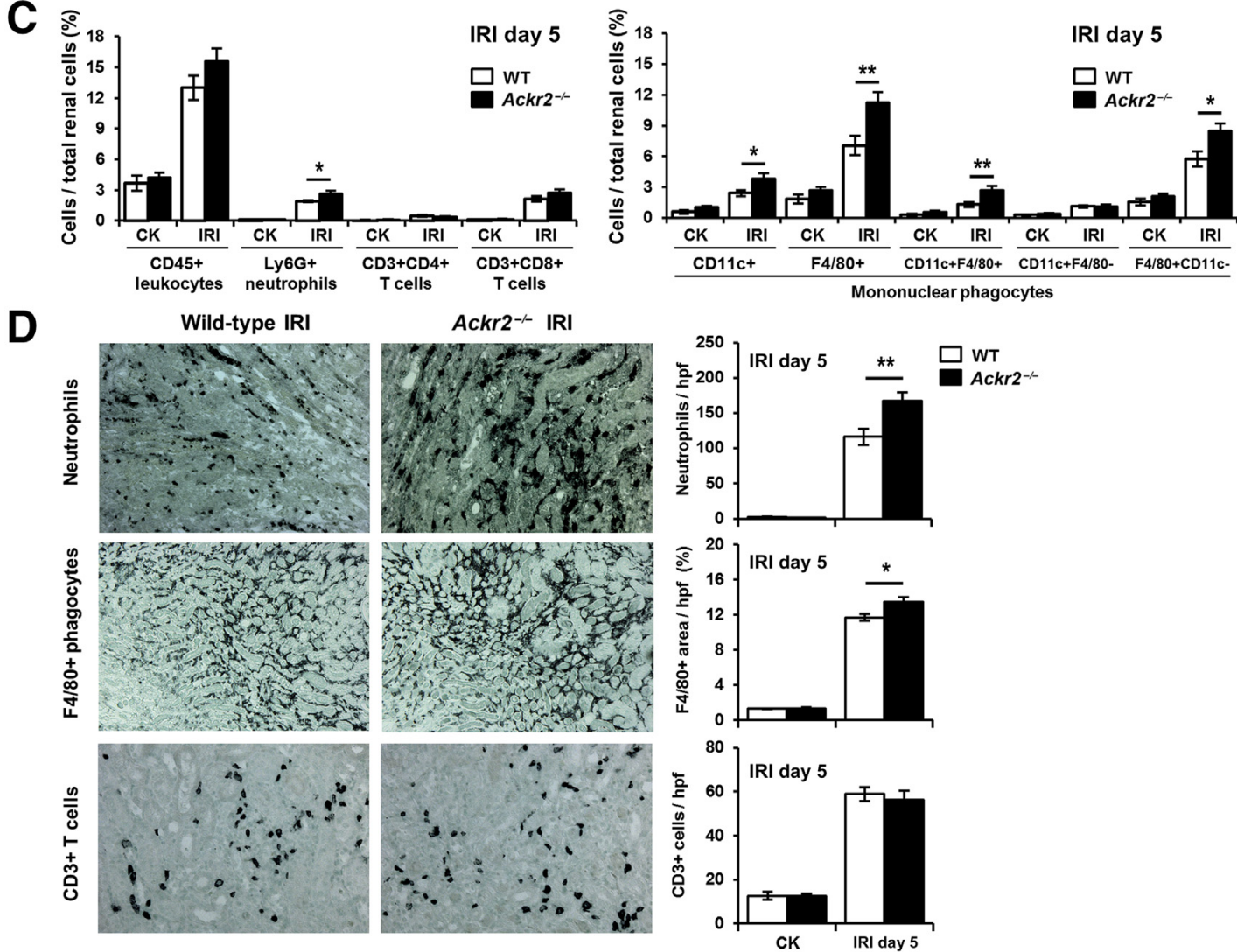

Figure 3 Ackr2 deficiency does not affect tubular injury and loss but leads to persistently elevated intrarenal leukocyte accumulation 5 days after renal ischemia-reperfusion injury (IRI). Wild-type (WT) and $A c k \mathrm{r}^{-/-}$mice were subjected to unilateral IRI for 45 minutes. Contralateral (CK) and postischemic kidneys (IRI) were analyzed 5 days after surgery. A: Similar tubular injury in postischemic kidneys of both groups of mice was demonstrated by semiquantitative morphometry of periodic acid-Schiff (PAS) - stained sections and comparable staining of postischemic kidneys with Lotus tetragonolobus lectin to identify proximal tubules at day 5 after IRI. B: Renal protein levels of kidney injury molecule (KIM)-1 as well as mRNA expression of the kidney injury markers KIM-1, neutrophil gelatinase-associated lipocalin (NGAL), and tissue inhibitor of metalloproteinase 2 (TIMP2) significantly increase in postischemic Ackr2 ${ }^{-/-}$ kidneys, indicating aggravated tubular cell stress. C: Flow cytometry of renal single-cell suspensions reveals significantly increased infiltrates of Ly6G ${ }^{+}$ neutrophils and $\mathrm{CD} 11 \mathrm{c}^{+} \mathrm{F} 4 / 80^{+}$mononuclear phagocytes, but not $\mathrm{CD} 11 \mathrm{c}^{+} \mathrm{F} 4 / 80^{-}$dendritic cells in postischemic kidneys of $A c k r 2^{-/-}$mice. D: Representative renal sections of WT and Ackr2-deficient mice stained for neutrophils, $\mathrm{F} 4 / 80^{+}$interstitial mononuclear phagocytes, and $\mathrm{CD}^{+}{ }^{+} \mathrm{T}$ cells. Data are expressed as means \pm SEM. $n=5$ to 8 mice per group $(\mathbf{A}-\mathbf{D})$. ${ }^{*} P<0.05,{ }^{*} P<0.01$. Original magnifications: $\times 100(\mathbf{A}$, top row); $\times 25(\mathbf{A}$, bottom row); $\times 200(\mathbf{D}$, top and middle rows); $\times 400$ (D, bottom row). hpf, high-power field. 


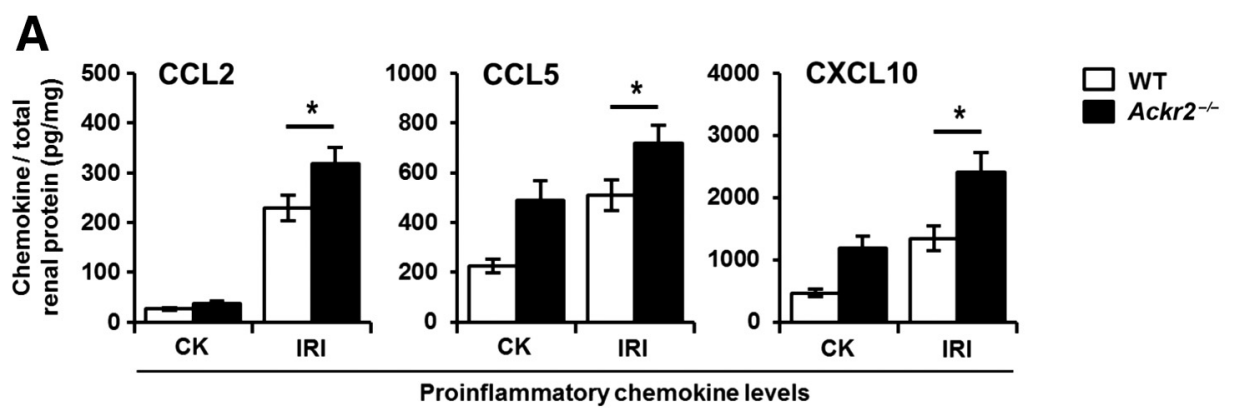

B
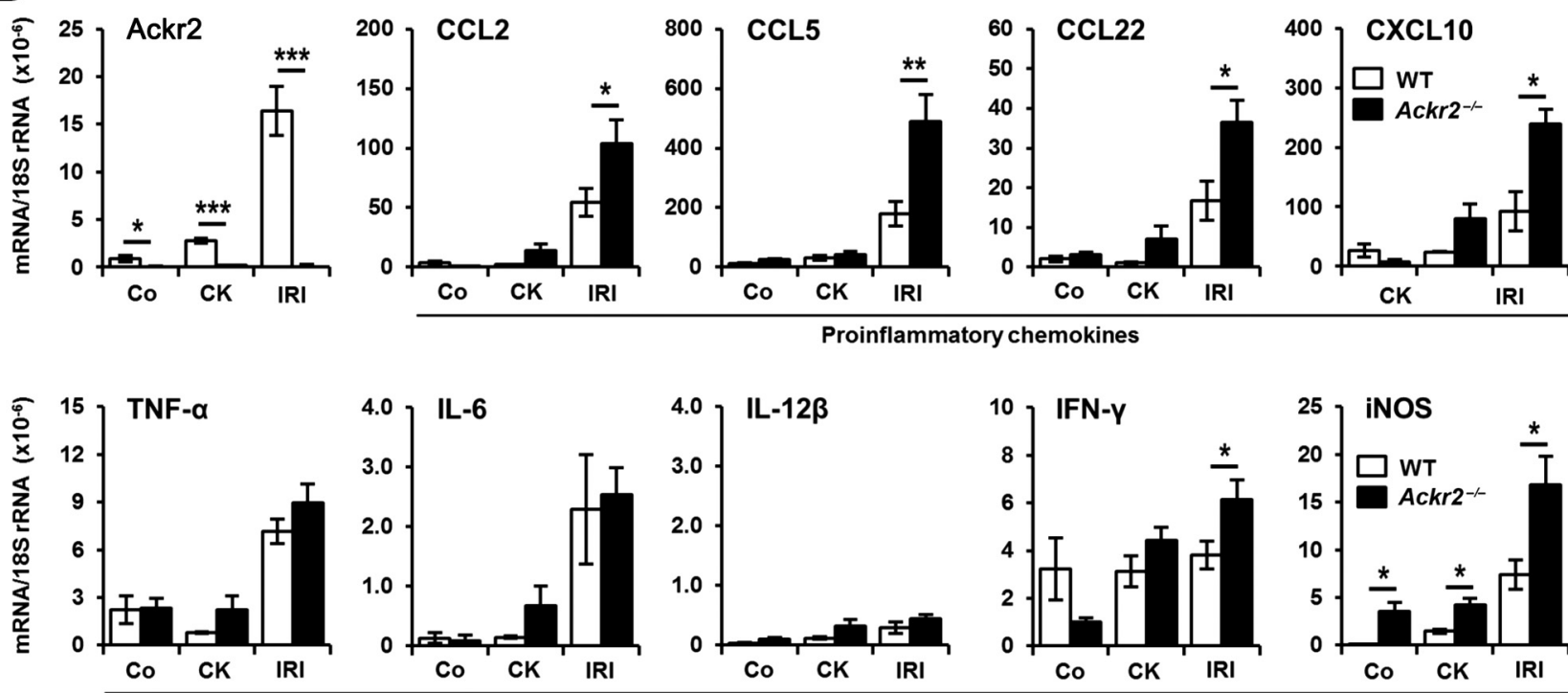

M1 macrophage expression markers
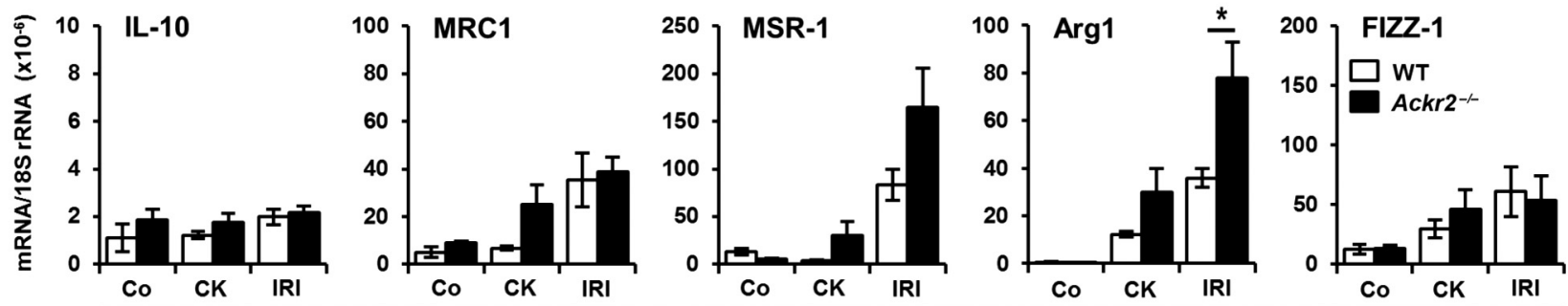

M2 macrophage expression markers

Figure 4 Renal chemokine levels and mRNA expression of inflammatory mediators in postischemic Ackr2-/- kidneys 5 days after renal ischemiareperfusion injury (IRI). A: Renal levels of proinflammatory chemokines, as determined by enzyme-linked immunosorbent assay, increased in IRI kidneys of $A c k r 2^{-/-}$mice at day 5 after IRI. B: Expression of ACKR2 was induced in postischemic wild-type (WT) kidneys compared with uninjured control (Co) and contralateral kidneys (CK) and is absent in Ackr2 ${ }^{-/-}$kidneys. Ackr2-deficient healthy and contralateral kidneys reveal an induced constitutive expression of inducible nitric oxide synthase (iNOS), whereas mRNA levels of other proinflammatory chemokines and macrophage markers were comparable in both genotypes. In contrast, in postischemic $A c k r 2^{-1-}$ kidneys, expression of proinflammatory chemokines and the macrophage markers interferon (IFN)- $\gamma$, macrophage scavenger receptor (MSR)-1, and arginase (Arg) 1 increases. Data are expressed as means \pm SEM. $n=5$ mice per group (B, Co); $n=8$ mice per group (B, CK and IRI). ${ }^{*} P<0.05,{ }^{*} P<0.01$, and ${ }^{* * *} P<0.001$. CCL, chemokine (C-C motif) ligand; FIZZ-1, a resistin-like protein markedly induced by IL-4 and IL-13; MRC, mannose receptor; TNF, tumor necrosis factor.

wild-type and $A c k r 2^{-/-}$mice by clamping both renal pedicles for 30 minutes, and the kidneys were subsequently harvested 24 hours after surgery. Lack of ACKR2 had no obvious effect on renal functional parameters, as evidenced by the similar increases seen in creatinine and urea in wildtype and $A c k r 2^{-/-}$mice (Figure 2A). Tubular injury by histology (Figure 2B) as well as renal protein and mRNA expression of the tubular damage marker KIM-1 (Figure 2C) were comparable in both groups. Renal CCL2 protein content was similar in wild-type and $A c k r 2^{-/-}$mice at this time point (Figure 2C). However, intrarenal leukocyte infiltration, which was comparable in control kidneys of 
A
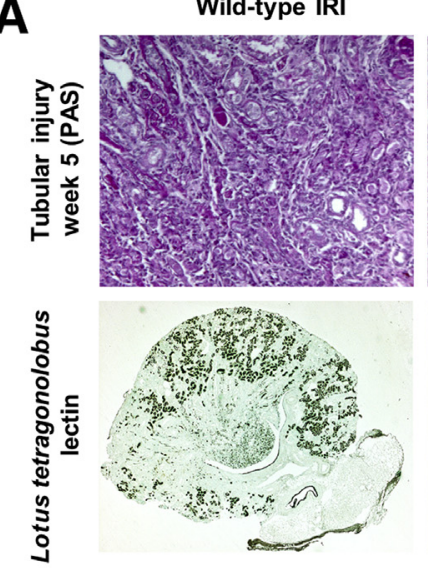

B

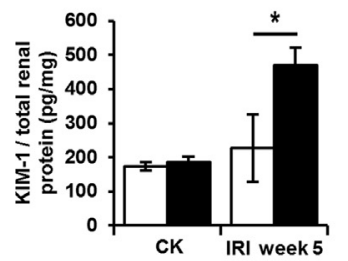

Ackr2 $^{--}$IRI
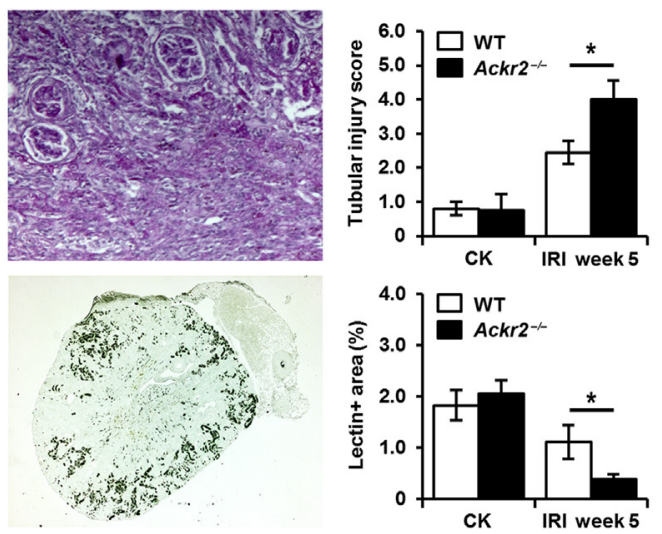
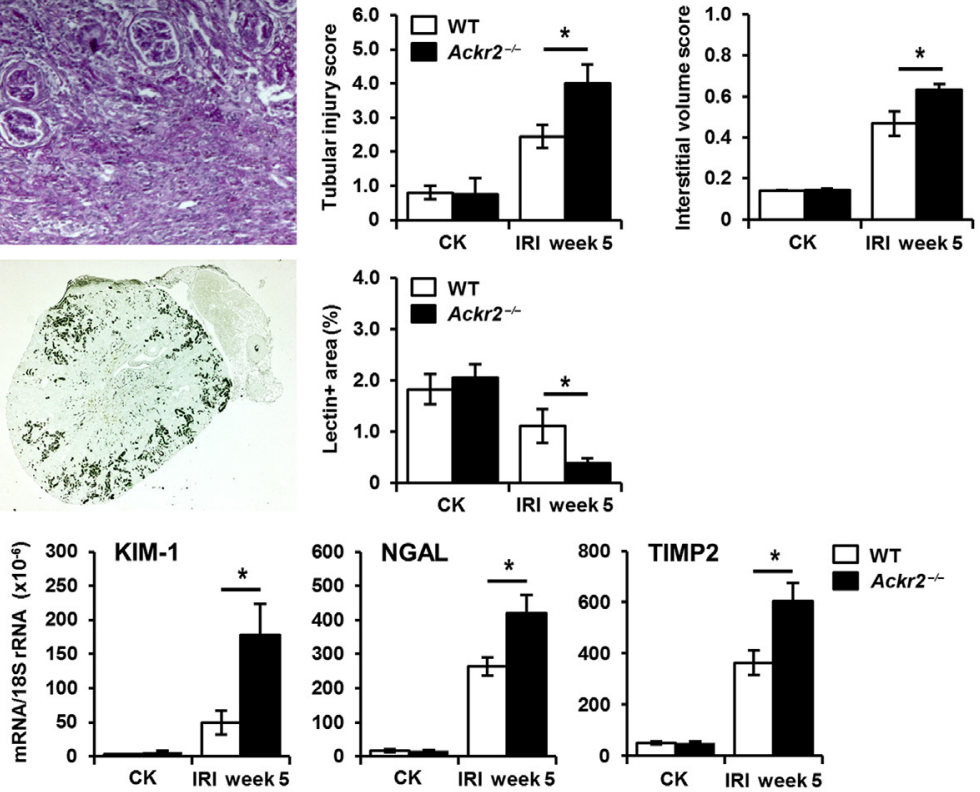

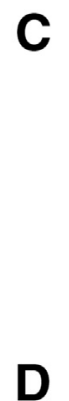

D

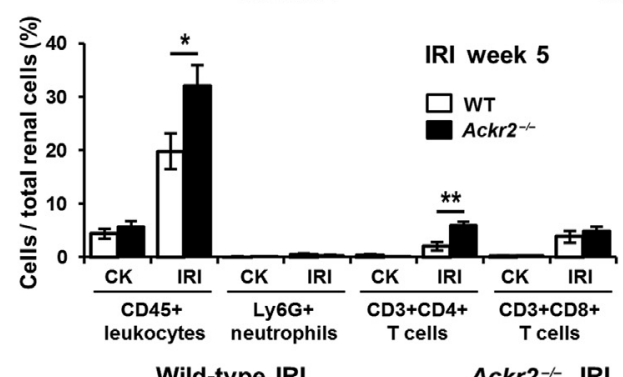

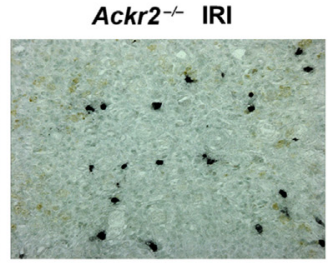

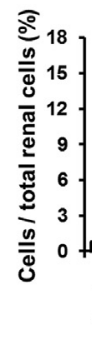
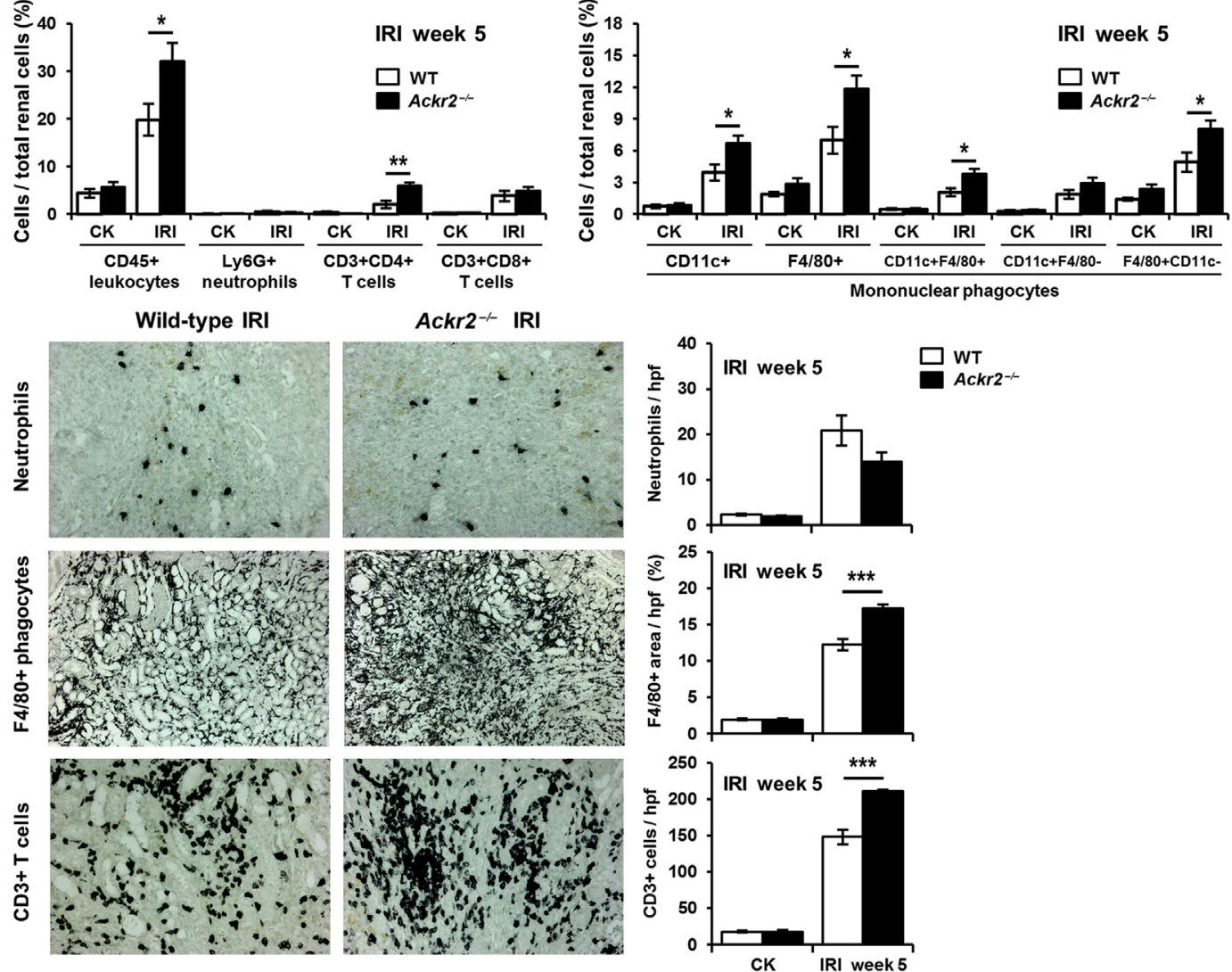

Figure 5 Ackr2 deficiency results in increased tubular injury and loss associated with more extensive intrarenal leukocyte accumulation 5 weeks after renal ischemia-reperfusion injury (IRI). Wild-type (WT) and $A c k 2^{-1-}$ mice were subjected to unilateral IRI for 45 minutes. Contralateral (CK) and postischemic kidneys (IRI) were analyzed 5 weeks after surgery A: Semiquantitative morphometry of periodic acid-Schiff (PAS)-stained sections and staining of postischemic kidneys with Lotus tetragonolobus lectin demonstrate significantly increased tubular injury, interstitial volume expansion, and tubular loss in postischemic $A c k r 2^{-/-}$kidneys at week 5 after IRI. B: Renal protein levels of kidney injury molecule (KIM)-1 and mRNA expression of the kidney injury markers KIM-1, neutrophil gelatinase-associated lipocalin (NGAL), and tissue inhibitor of metalloproteinase 2 (TIMP2) are significantly increased in Ackr2 ${ }^{-/-}$kidneys. C: Flow cytometric analysis reveals significant increases in intrarenal $\mathrm{CD}_{4} 5^{+}$leukocytes, $\mathrm{CD}^{+} \mathrm{T}$ cells, and $\mathrm{CD} 11 \mathrm{c}^{+} \mathrm{F} / 80^{+}$mononuclear phagocytes in postischemic $A c k r 2^{-/-}$kidneys compared with WT kidneys. D: Representative immunohistochemistry of renal tissue obtained from WT and Ackr2-deficient mice 5 weeks after IRI stained for neutrophils, $\mathrm{F} 4 / 80^{+}$interstitial mononuclear phagocytes, and $\mathrm{CD} 3^{+} \mathrm{T}$ cells demonstrates significantly enhanced accumulation of phagocytes and T cells in postischemic $A c k r 2^{-/-}$kidneys. Data are expressed as means \pm SEM. $n=8$ mice per group $(\mathbf{A}-\mathbf{D})$. ${ }^{*} P<0.05, * * P<0.01$, and $* * * P<0.001$. Original magnifications: $\times 100$ (A, top row); $\times 25$ (A, bottom row); $\times 400$ (D, top and bottom rows); $\times 200$ (D, middle row). 
A

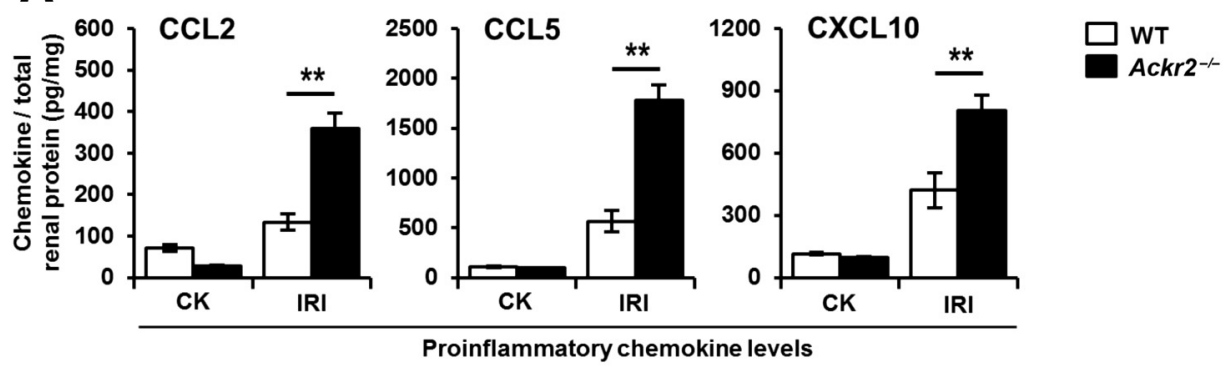

B
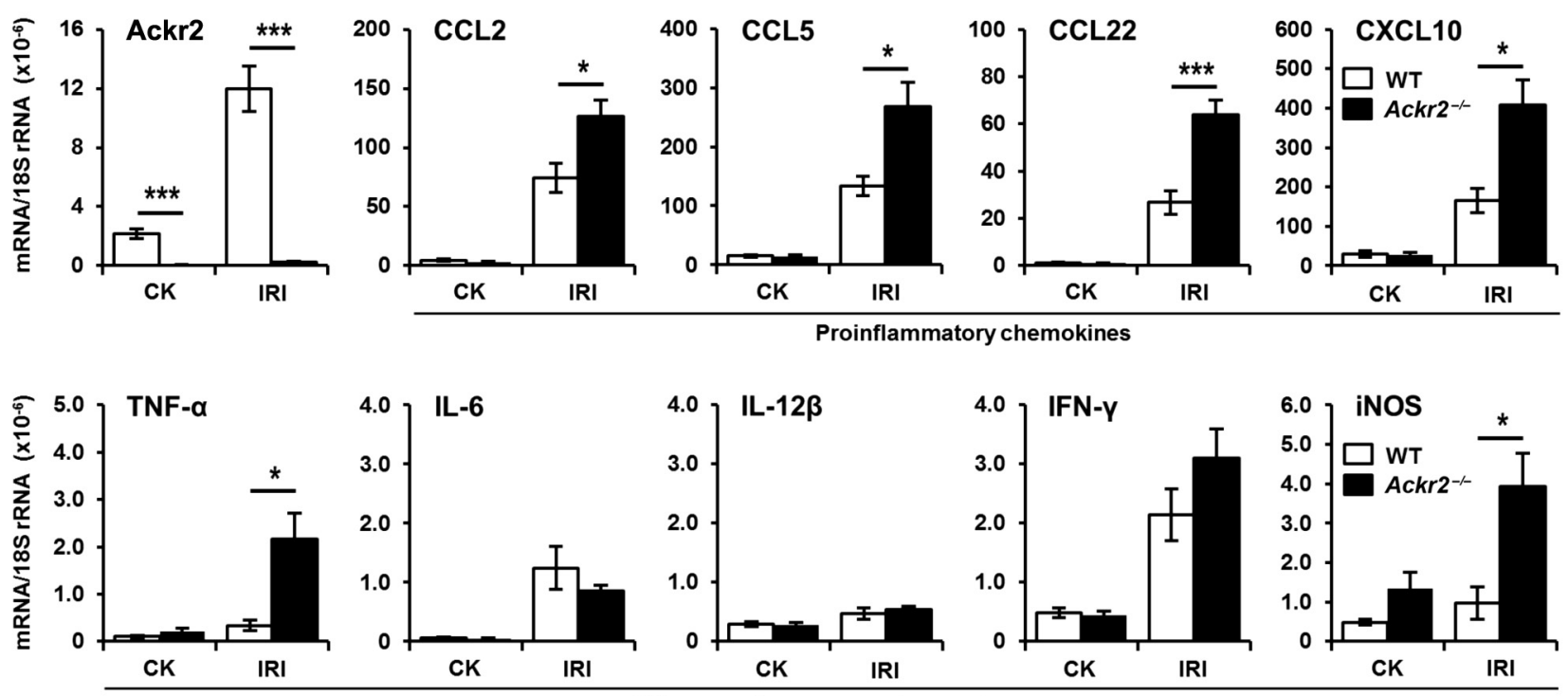

M1 macrophage expression markers

C

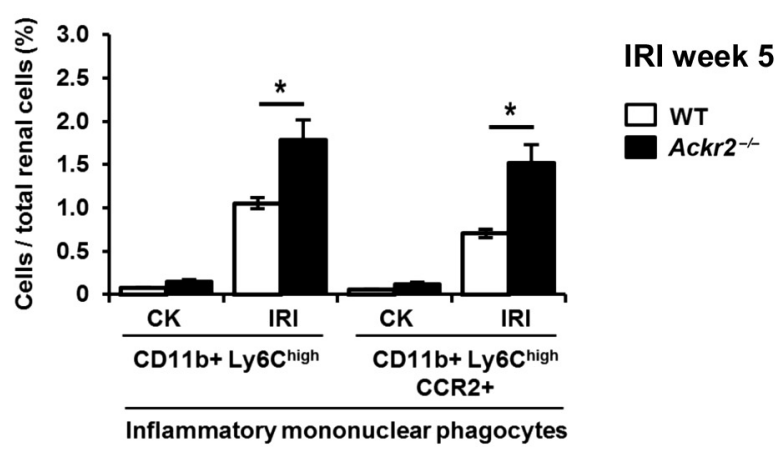

Figure 6 Increased renal chemokine levels are associated with aggravated inflammation in postischemic Ackr2 ${ }^{-1-}$ kidneys 5 weeks after renal ischemiareperfusion injury (IRI). A: Renal levels of proinflammatory chemokines were determined by enzyme-linked immunosorbent assay in contralateral (CK) and postischemic (IRI) kidney tissue of wild-type (WT) and Ackr2 ${ }^{-1-}$ mice at week 5 after unilateral IRI for 45 minutes, as described in Materials and Methods. B: Expression of Ackr2 is induced in postischemic WT kidneys compared with contralateral kidneys and absent in $A c k r 2^{-/-}$kidneys. Expression of proinflammatory chemokines and M1 macrophage markers is more abundant in postischemic $A c k r 2^{-/-}$kidneys. C: Flow cytometry of renal single-cell suspensions reveals a significantly increased accumulation of $\mathrm{CD} 11 \mathrm{~b}^{+}$Ly6 $\mathrm{C}^{\text {high }}$ inflammatory macrophages in postischemic $A c k r 2^{-/-}$kidneys, which expressed the chemokine (C-C motif) ligand (CCL) 2 receptor CCR2. Data are expressed as means \pm SEM. $n=5$ to 9 mice per group $(\mathbf{A}-\mathbf{C}) .{ }^{*} P<0.05,{ }^{*} P<0.01$, and ${ }^{* * *} P<0.001$. IFN, interferon; iNOS, inducible nitric oxide synthase; TNF, tumor necrosis factor.

healthy wild-type and $A c k r 2^{-/-}$mice, was moderately increased in $A c k r 2^{-1-}$ kidneys at 24 hours after IRI, being significant for $\mathrm{CD} 11 \mathrm{c}^{+} \mathrm{F} 4 / 80^{+}$mononuclear phagocytes when analyzed by flow cytometry (Figure 2D), with a similar trend seen in immunohistochemistry (Figure 2E).
Taken together, these results indicate that $A c k r 2$ deficiency did not affect severity of the initial ischemic kidney injury but enhanced early accumulation of some phagocytic leukocyte subsets in ischemic kidneys during the first 24 hours after IRI. This may relate to potential systemic 

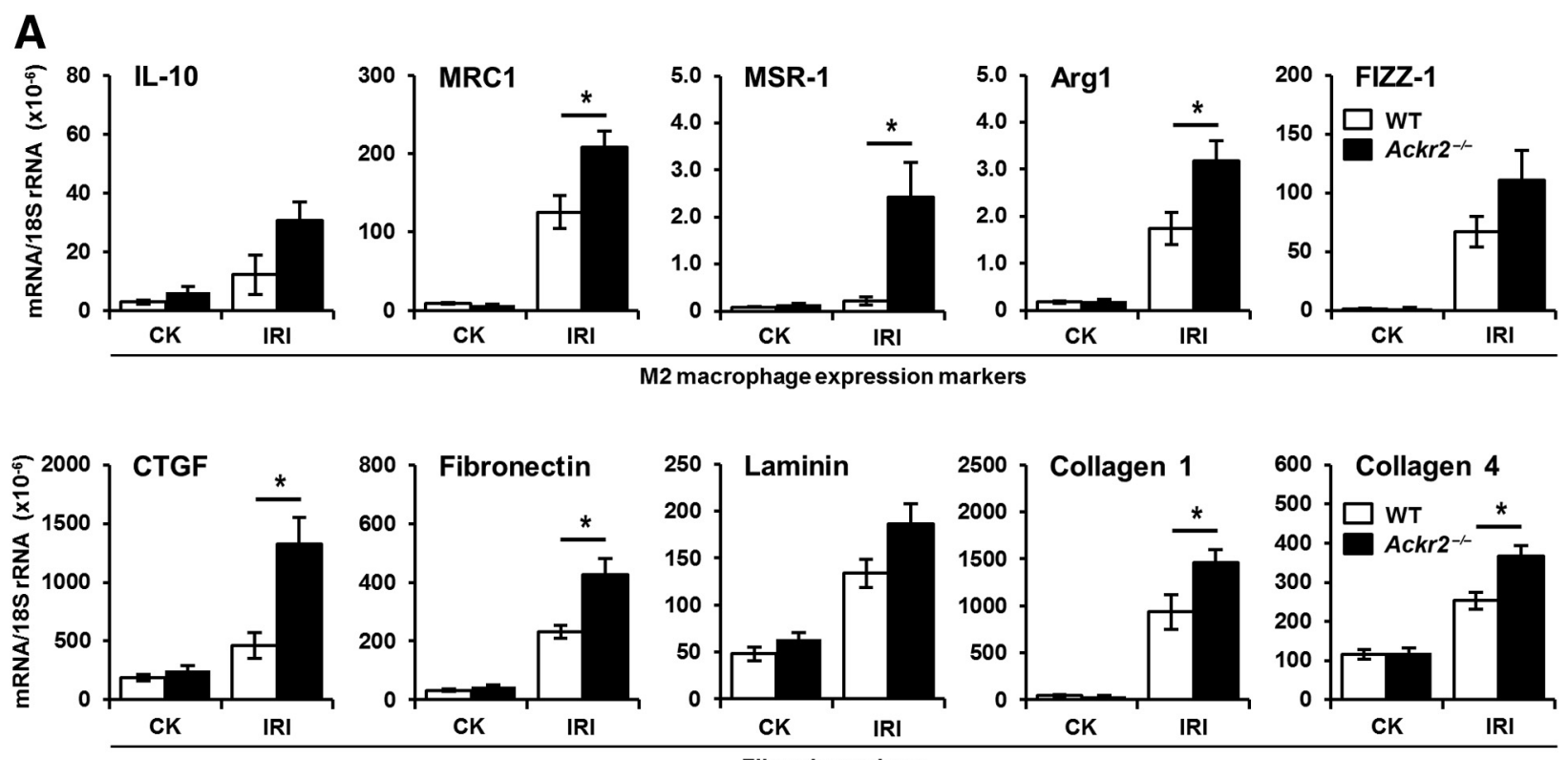

Fibrosis markers

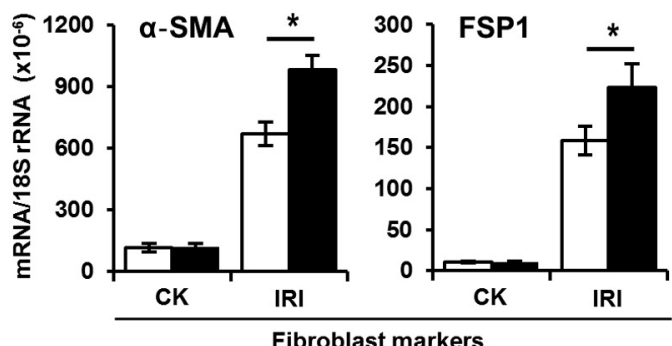

B

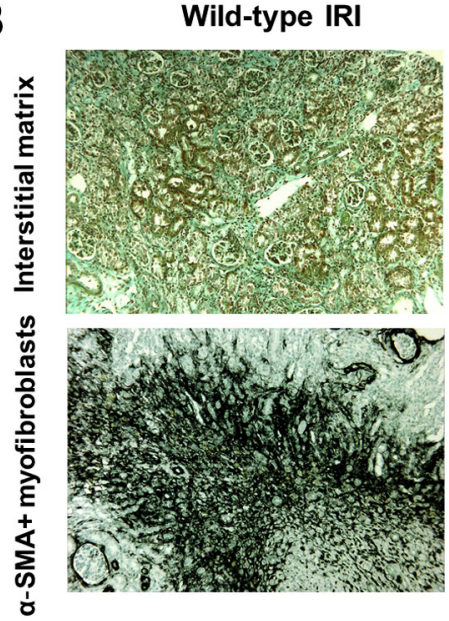

Ackr2 ${ }^{-/}$IRI
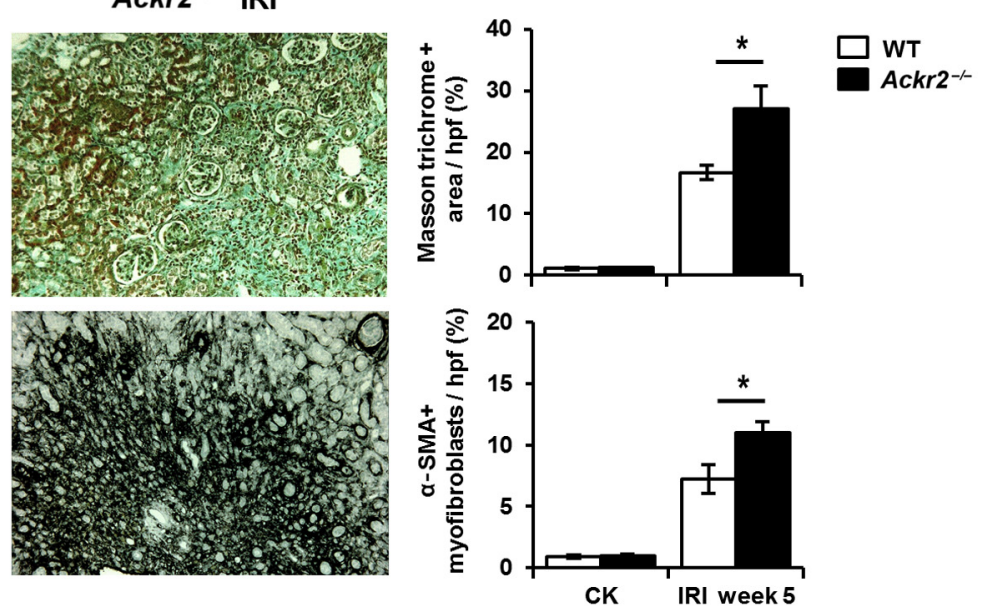

C
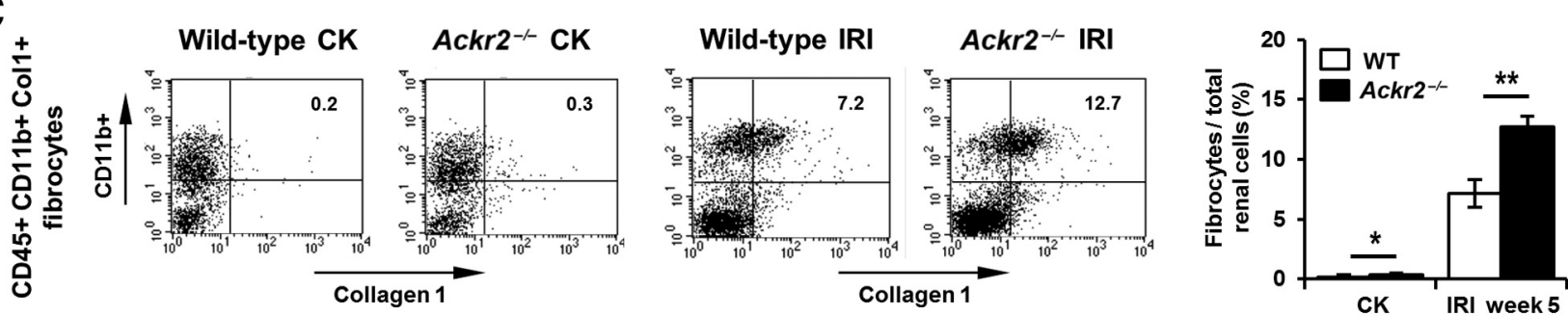
ACKR2 effects because intrarenal chemokine levels were not increased at this time point.

\section{Ackr2 Deficiency Leads to Persistent Increases in Renal Leukocyte Numbers during the Early Recovery Phase after Unilateral IRI}

It was next investigated whether lack of ACKR2 would persistently elevate intrarenal leukocyte numbers during the early recovery phase after AKI, which could also lead to more extensive injury. To this end, wild-type and $A c k r 2^{-/-}$ kidneys were analyzed 5 days after 45 minutes of unilateral renal pedicle clamping. Histology revealed comparable structural injury in both genotypes, as demonstrated by similar tubular injury and interstitial volume scores, and similar staining of tubules with $L$. tetragonolobulus lectin (Figure 3A). However, renal KIM-1 protein levels and mRNA expression of the tubular injury markers KIM-1 (official name, HAVCR1), neutrophil gelatinase-associated lipocalin (official name, LCN2), and tissue inhibitor of metalloproteinase 2 (TIMP2) were increased in ischemic $A c k r 2^{-1-}$ kidneys (Figure 3B). Moreover, renal leukocytes were significantly elevated in $A c k r 2^{-/-}$kidneys 5 days after IRI, including neutrophils and $\mathrm{CD} 11 \mathrm{c}^{+} \mathrm{F} 4 / 80^{+}$mononuclear phagocytes, but not $\mathrm{CD} 11 \mathrm{c}^{+} \mathrm{F} 4 / 80^{-}$dendritic cells or $\mathrm{T}$ cells (Figure 3C). Flow cytometric analysis was confirmed by immunohistochemistry, which localized increased renal infiltrates of neutrophils and $\mathrm{F} 4 / 80^{+}$ phagocytes in $A c k r 2^{-/}$mice to the corticomedullary junction, which is the major site of ischemic tubular damage (Figure 3D). Consistently, renal levels and mRNA expression of inflammatory chemokines, as well as some M1 and M2 macrophage markers, increased in postischemic Ackr2 ${ }^{-/-}$ kidneys (Figure 4). Of importance, baseline expression of these inflammatory mediators in uninjured kidneys of healthy wild-type and $A c k r 2^{-1-}$ mice was similar, with the only exception being a significantly induced constitutive expression of inducible nitric oxide synthase in Ackr2deficient kidneys (Figure 4). Together, these data indicate that $A c k r 2$ deficiency resulted in persistently elevated numbers of renal neutrophils and macrophages during the early recovery phase after IRI. This was associated with increased expression of tubular cell stress markers and inflammatory mediators in postischemic kidneys, but did not affect the extent of tubular structural injury or loss.
Persistently Elevated Leukocyte Infiltrates Are Associated with Increased Tubular Injury in Ackr2Deficient Kidneys 5 Weeks after Unilateral IRI

To further explore potential roles of ACKR2 in renal regeneration versus progression to $\mathrm{CKD}$, wild-type and $A c k r 2^{-/-}$mice were analyzed 5 weeks after 45 minutes of unilateral renal pedicle clamping. Postischemic Ackr2 ${ }^{-/-}$ kidneys displayed significantly more tubular damage and loss, as revealed by a higher tubular injury and interstitial volume scores, and reduced $L$. tetragonobulus lectin staining (Figure 5A). Consistently, KIM-1 protein expression and mRNA expression of tubular injury markers increased in $A c k r 2^{-/-}$kidneys (Figure 5B). This was associated with increased numbers of intrarenal leukocytes, with enhanced accumulation of $\mathrm{CD} 11 \mathrm{c}^{+} \mathrm{F} 4 / 80^{+}$phagocytes and $\mathrm{CD} 4^{+} \mathrm{T}$ cells, as characterized by flow cytometry (Figure 5C). Immunohistochemistry confirmed increased tubulointerstitial infiltrates of $\mathrm{F} 4 / 80^{+}$macrophages and $\mathrm{CD}^{+} \mathrm{T}$ cells in $A c r k 2^{-/-}$kidneys 5 weeks after IRI (Figure 5D). Thus, lack of Ackr2 results in persistent increases of intrarenal mononuclear leukocyte infiltrates in postischemic kidneys during the regeneration phase, which was associated with more severe tubular injury and atrophy.

\section{Lack of Ackr2 Promotes Renal Inflammation and Inflammatory Macrophage Infiltrates in Postischemic Kidneys}

Protein levels of the proinflammatory chemokines CCL2, CCL5, and CXCL10 were significantly elevated in postischemic $A c k r 2^{-/-}$kidneys (Figure 6A). Together with our previous findings demonstrating increased CCL2 levels in tumor necrosis factor- $\alpha$-stimulated Ackr2-deficient tubulointerstitial tissue in vitro, ${ }^{27}$ these results are consistent with a defect in chemokine clearance in Ackr2-deficient kidneys. In addition, chemokines expressed by the higher number of attracted leukocytes may subsequently contribute to increased renal levels. Persistent intrarenal leukocyte infiltrates with ongoing inflammation may prevent tubular repair in $A c k r 2^{-1-}$ mice after IRI. Therefore, it was investigated whether increased tubular injury was paralleled by the expression of inflammatory mediators in postischemic kidneys 5 weeks after IRI. As expected, ACKR2 expression was absent in $A c k r 2^{-/-}$kidneys. Ackr2 deficiency was

\footnotetext{
Figure 7 Ackr2 deficiency results in increased renal fibrosis in postischemic kidneys 5 weeks after renal ischemia-reperfusion injury (IRI). A: mRNA expression levels of M2 macrophage markers, fibrosis-associated molecules, extracellular matrix molecules, and fibroblast markers were determined in contralateral (CK) and postischemic (IRI) kidneys of wild-type (WT) and Ackr2 ${ }^{-/-}$mice. B: Masson trichrome staining reveals increased interstitial matrix deposition in postischemic $A c k r 2^{-/-}$kidneys, and immunohistochemistry confirms an enhanced accumulation of $\alpha$-smooth muscle actin ( $\alpha$-SMA) ${ }^{+}$myofibroblasts in postischemic $A c k r 2^{-/-}$kidneys compared with WT kidneys. C: Increased intrarenal accumulation of CD45 $5^{+}$CD11b ${ }^{+}$collagen $1^{+}$fibrocytes in postischemic $A c k r 2^{-/-}$kidneys compared with WT kidneys, as quantified by flow cytometric analysis. Representative fluorescence-activated cell sorting plots gated on $\mathrm{CD}_{4} 5^{+}$renal cells are shown for CK and IRI kidneys of WT and $A c \mathrm{Kr}^{-1-}$ mice. Numbers shown are the mean percentage of renal fibrocytes per total renal cells in each group. Data are expressed as means \pm SEM. $n=5$ to 9 mice per group $(\mathbf{A}-\mathbf{C})$. ${ }^{*} P<0.05,{ }^{* *} P<0.01$. Original magnification, $\times 200$ (B). Arg, arginase; CTGF, connective tissue growth factor; FIZZ-1, a resistin-like protein markedly induced by IL-4 and IL-13; FSP, fibroblast-specific protein; hpf, high-power field; MRC, mannose receptor; MSR, macrophage scavenger receptor.
} 

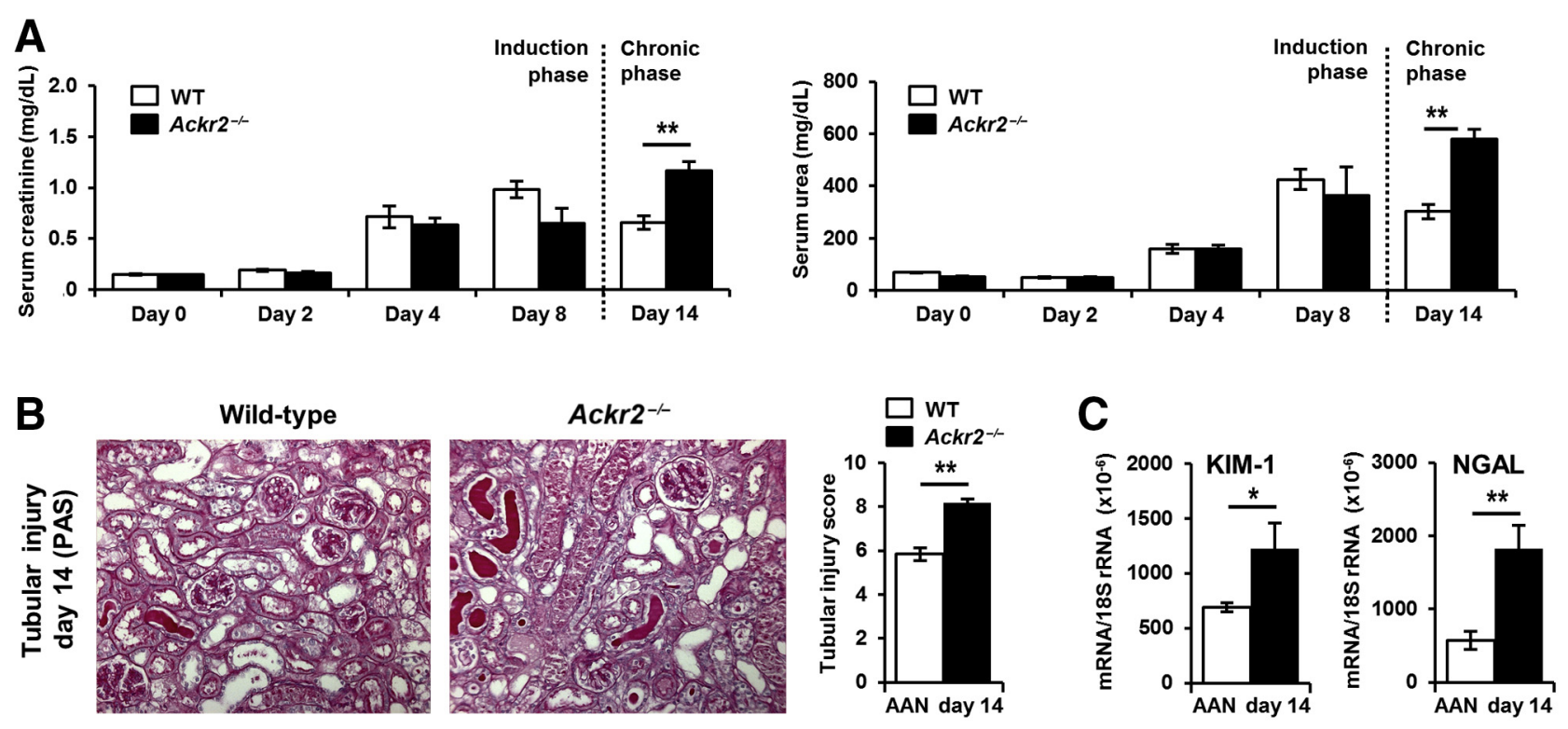

D
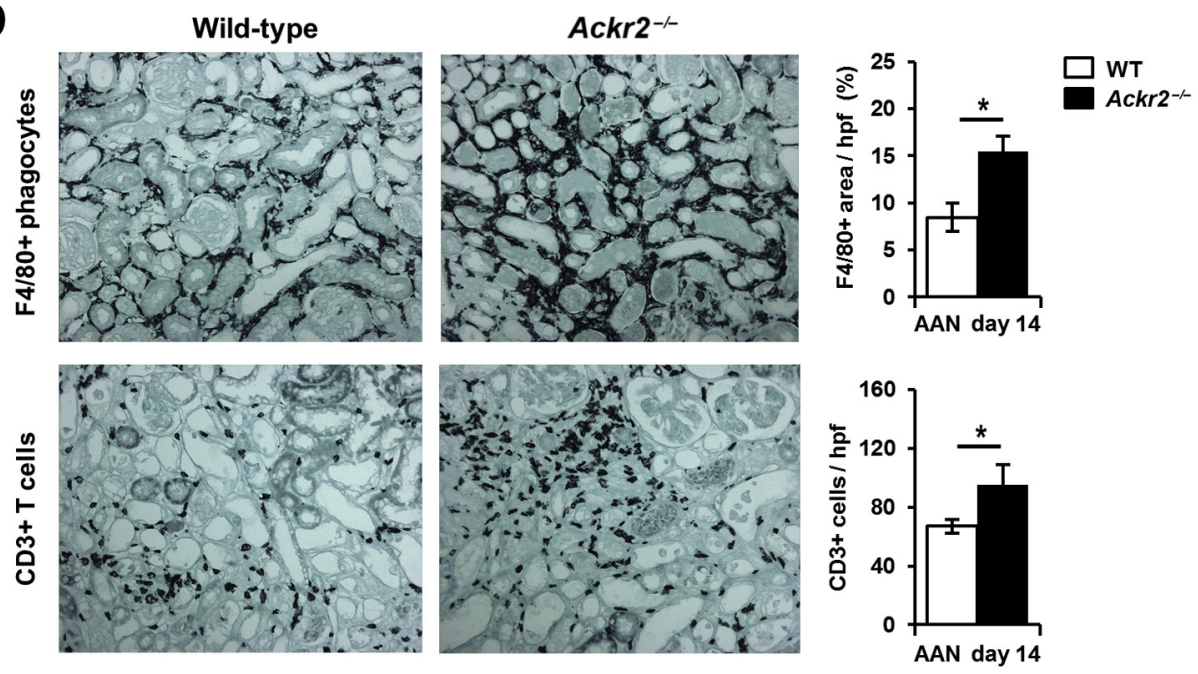

E
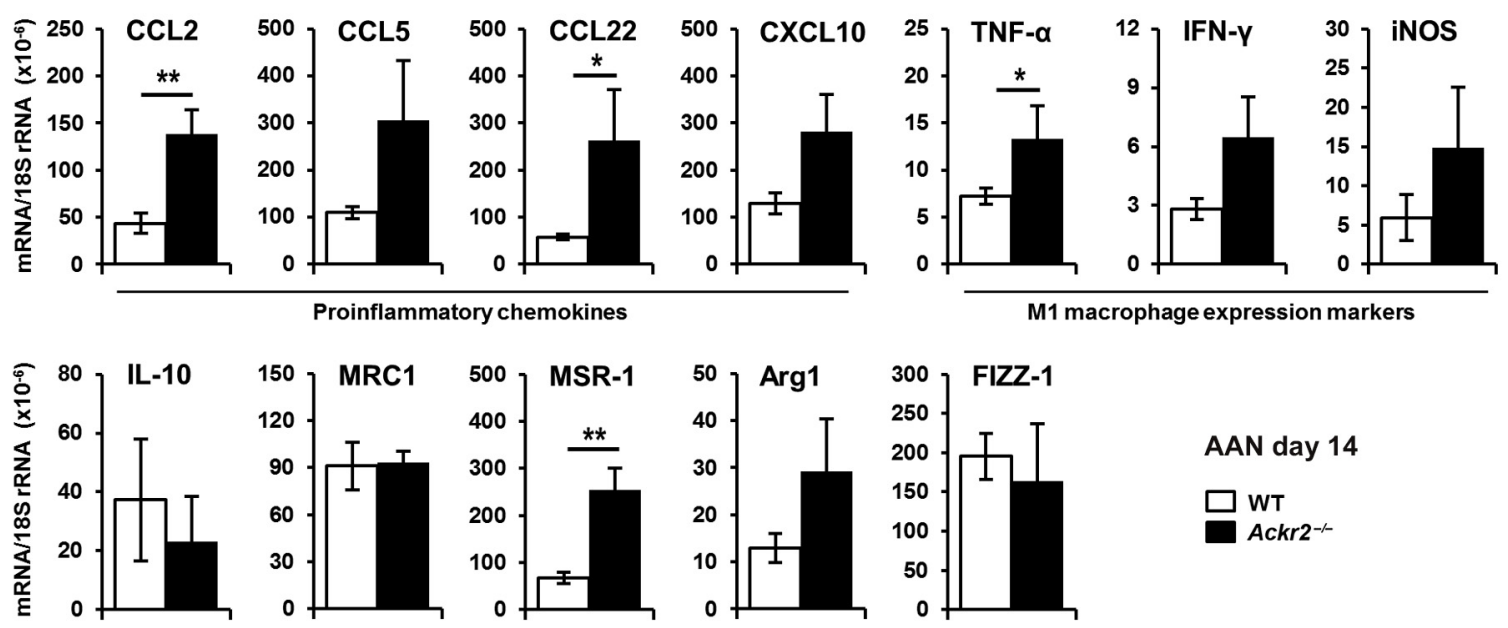

AAN day 14

$\square$ WT

Ackr2--

M2 macrophage expression markers 
associated with significantly elevated renal mRNA expression of the proinflammatory chemokines CCL2, CCL5, CCL22, and CXCL10 (Figure 6B), all known to be expressed by activated proinflammatory macrophages. ${ }^{28}$ Moreover, mRNA levels of M1 macrophage markers, expressed by classically activated proinflammatory mononuclear phagocytes, were increased in $A c k r 2^{-/-}$kidneys (Figure 6B). Consistently, flow cytometric analysis demonstrated significantly higher numbers of intrarenal $\mathrm{CD}_{11 \mathrm{~b}^{+}}$Ly6C $\mathrm{C}^{\text {high }}$ inflammatory macrophages in postischemic kidneys of $A c k r 2^{-/}$mice, most of which also expressed the CCL2 receptor CCR2 (Figure 6C). These data suggest that increased renal levels of inflammatory chemokines, including CCL2, augment accumulation of mononuclear leukocytes in postischemic $A c k r 2^{-/-}$kidneys in vivo, including $\mathrm{CCR} 2^{+}$inflammatory macrophages. This results in persistently aggravated tubulointerstitial inflammation and increased tubular injury in $A c k r 2^{-1-}$ mice.

\section{Increased Tubular Injury and Inflammation Is Associated with More Severe Interstitial Fibrosis in Postischemic Kidneys of Ackr2 ${ }^{-/-}$Mice}

CKD after AKI is characterized by fibrotic remodeling of renal interstitial tissue, with loss of nephrons paralleled by progressive accumulation of extracellular matrix and fibrogenic cells. ${ }^{5,6}$ Increased tubulointerstitial inflammation in postischemic $A c k r 2^{-1-}$ kidneys may help drive this fibrotic response, in particular when associated with an accumulation of alternatively activated M2 macrophages thought to mediate matrix deposition and tissue remodeling. ${ }^{28}$ Indeed, mRNA levels of M2 macrophage markers were increased in postischemic kidneys of $A c k r 2^{-1-}$ mice 5 weeks after IRI (Figure 7A). Moreover, significantly increased mRNA expression of fibrosis markers, extracellular matrix components, $\alpha$-SMA, and fibroblast-specific protein 1 suggested enhanced fibrosis in $A c k r 2^{-/-}$kidneys (Figure 7A). Masson trichrome staining revealed significantly enhanced matrix deposition, and immunohistochemistry showed an increased accumulation of $\alpha-\mathrm{SMA}^{+}$myofibroblasts in postischemic $A c k r 2^{-/-}$kidneys (Figure 7B). By contrast, at day 5 after IRI, the extent of fibrotic remodeling was similar to wild type (Supplemental Figure S1), despite enhanced leukocyte infiltration and inflammation in Ackr2 $2^{-/-}$kidneys in the early recovery phase after IRI.
Bone marrow-derived fibrocytes have been proposed to contribute to renal fibrosis in postischemic kidneys. ${ }^{26,29}$ Because fibrocytes express CCR $2,{ }^{26}$ increased abundance of its ligand CCL2 in Ackr2-deficient tubulointerstitial tissue could help foster fibrocyte migration into postischemic Ackr2 $2^{-/-}$kidneys. Renal $\mathrm{CD}_{4} 5^{+} \mathrm{CD} 11 \mathrm{~b}^{+}$collagen $1^{+}$ fibrocytes were, therefore, analyzed in kidneys 5 weeks after IRI by flow cytometry, which revealed a significant increase in fibrocytes in $A c k r 2^{-1-}$ kidneys (Figure 7C).

Taken together, $A c k r 2$ deficiency not only results in more severe tubular injury associated with sustained accumulation of intrarenal leukocytes and inflammation, but also in significantly aggravated renal fibrosis in postischemic kidneys 5 weeks after IRI, which is a characteristic finding in CKD after AKI.

\section{CCL2 Levels and Leukocyte Counts in Blood Increase in Ackr2-Deficient Mice}

Analysis of systemic effects of Ackr2 deficiency revealed significantly elevated CCL2 serum levels in Ackr2 ${ }^{-1-}$ mice 5 weeks after IRI (Supplemental Figure S2A). This was paralleled by increased peripheral leukocyte counts in Ackr2-deficient mice, with significant higher numbers of circulating neutrophils, dendritic cells, monocytes, and, particularly, inflammatory $\mathrm{CD}_{11 b^{+}}$Ly6 $\mathrm{C}^{\text {high }}$ monocytes expressing CCR2 (Supplemental Figure S2B). No differences in leukocyte numbers were evident in spleen, but a tendency toward reduced leukocyte counts was noted in $A c k r 2^{-l-}$ bone marrow, with significantly reduced numbers of $\mathrm{CD}_{11 b^{+}}$Ly6C $\mathrm{C}^{\text {high }}$ monocytes expressing CCR2 (Supplemental Figure S2B). These results could indicate increased mobilization of $\mathrm{CCR} 2^{+}$monocytes from bone marrow, potentially mediated by elevated systemic levels of the respective chemokine ligands in $A c k r 2^{-/-}$mice. ${ }^{30-32}$ Thus, higher numbers of circulating inflammatory monocytes may contribute to increased renal leukocyte infiltration and inflammation in $A c k r 2$-deficient mice.

\section{Ackr2 Deficiency Does Not Affect Renal Fibrosis in Hydronephrotic Kidneys after UUO}

It was further investigated whether impaired renal chemokine clearance in $A c k r 2^{---}$kidneys could aggravate inflammatory responses and fibrosis in obstructive nephropathy induced by

Figure 8 Renal injury, leukocyte accumulation, and inflammation in wild-type (WT) and $A c k 2^{-/-}$mice with aristolochic acid-induced nephropathy (AAN). A: Increases in serum creatinine and urea were comparable in WT and $A c k 2^{-1-}$ mice during the induction phase of the model, indicating similar initial renal injury in both genotypes. At day 14 of AAN, renal function was significantly worse in $A c k r 2^{-1-}$ mice compared with WT mice. The dashed lines separate data of the induction and chronic phases. B: Tubular injury, as evaluated by semiquantitative scoring of periodic acid-Schiff (PAS)-stained sections. C: Renal mRNA expression of tubular injury markers is aggravated in $A c k r 2^{-/-}$kidneys compared with WT kidneys at day 14. D: Representative renal sections illustrating increased infiltration of $\mathrm{F} 4 / 80^{+}$interstitial mononuclear phagocytes and $\mathrm{CD}^{+} \mathrm{T}$ cells in $\mathrm{Ackr}^{-/-}$mice. Leukocyte infiltrates were quantified as described in Materials and Methods. E: Increased renal mRNA expression of proinflammatory chemokines and several M1 and M2 macrophage markers in Ackr2 ${ }^{-1}$ kidneys after AAN. Data are expressed as means \pm SEM. $n=5$ to 6 mice per group (A-E). ${ }^{*} P<0.05,{ }^{*} P<0.01$. Original magnification, $\times 400$ (B and D). Arg, arginase; CCL, chemokine (C-C motif) ligand; FIZZ-1, a resistin-like protein markedly induced by IL-4 and IL-13; hpf, high-power field; IFN, interferon; iNOS, inducible nitric oxide synthase; KIM, kidney injury molecule; MRC, mannose receptor; MSR, macrophage scavenger receptor; NGAL, neutrophil gelatinaseassociated lipocalin; TNF, tumor necrosis factor. 


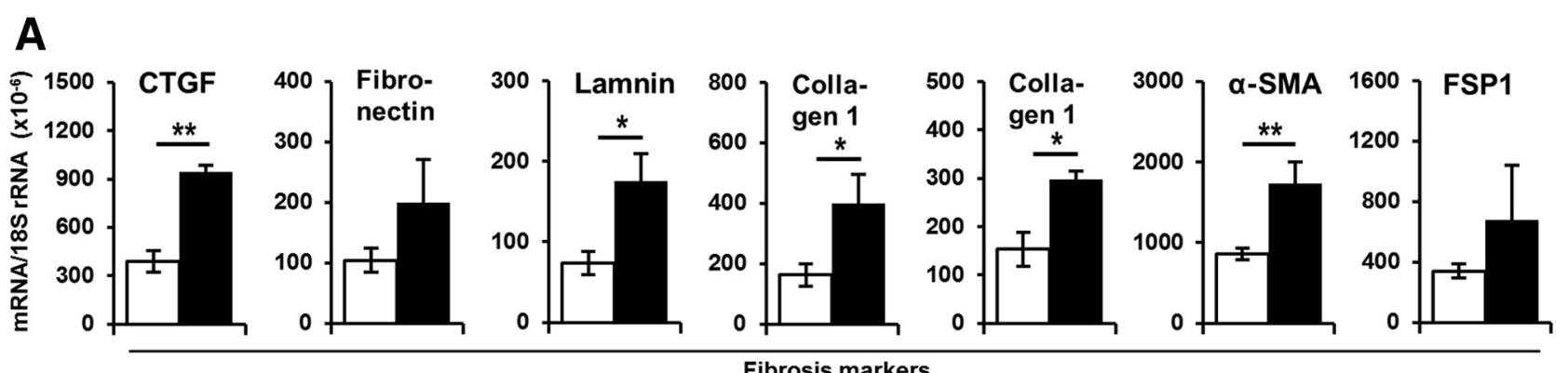

B

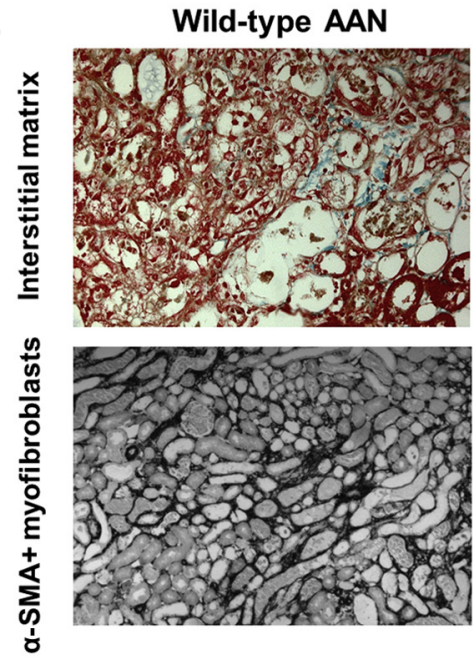

Ackr2-- $^{-1}$ AAN
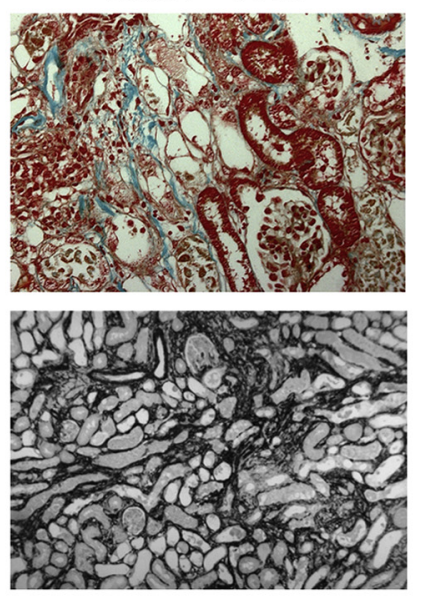
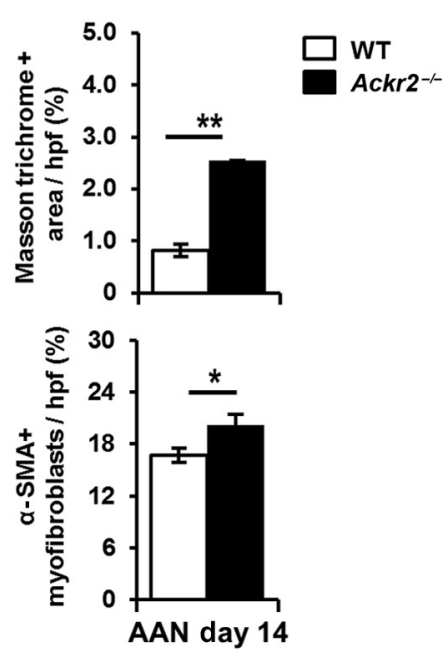

Figure 9 Renal fibrosis in wild-type (WT) and $A c k r 2^{-/-}$mice with aristolochic acid-induced nephropathy (AAN). A: Increased renal mRNA expression of fibrosis-associated molecules, extracellular matrix, and fibroblast markers in $A c k r 2^{-/-}$mice at day 14 after AAN. B: Increased interstitial matrix deposition and accumulation of $\alpha$-smooth muscle actin $(\alpha \text {-SMA })^{+}$myofibroblasts in injured $A c k r 2^{-1-}$ kidneys, as revealed by Masson trichrome staining and immunohistochemistry, respectively. Data are expressed as means \pm SEM. $n=5$ to 6 mice per group (A and $\mathbf{B}$ ). ${ }^{*} P<0.05,{ }^{*} P<0.01$. Original magnifications: $\times 400$ (B, top row); $\times 200$ (B, bottom row). CTGF, connective tissue growth factor; FSP, fibroblast-specific protein; hpf, high-power field.

UUO, a classic model for fibrotic remodeling in CKD. ${ }^{33}$ Unilateral ureter ligation for 7 and 14 days resulted in equal tubular dilation, tubular cell injury, and interstitial volume expansion in obstructed wild-type and $A c k r 2^{-1-}$ kidneys (Supplemental Figure S3A), with similar intrarenal accumulation of most leukocyte subsets (Supplemental Figure S3, B and C). Significant increases were found only in CD11c ${ }^{+}$ $\mathrm{F} 4 / 80^{-}$dendritic cells and $\mathrm{CD}^{+}{ }^{+}$cells in $A c k r 2^{-1-}$ mice by flow cytometry and immunohistochemistry, respectively (Supplemental Figure S3, B and C). Renal mRNA expression of KIM-1 and proinflammatory chemokines CCL2 and CCL5 was comparable, as were numbers of inflammatory $\mathrm{CD} 11 \mathrm{~b}^{+}$ Ly6 $\mathrm{C}^{\text {high }}$ macrophages in obstructed kidneys (Supplemental Figure S4, A and B). Renal expression of fibrotic markers and the accumulation of $\alpha$-SMA ${ }^{+}$myofibroblasts and fibrocytes were similar in obstructed wild-type and $A c k r 2^{-/-}$ kidneys (Supplemental Figure S4, C and D). Despite lacking a renal phenotype, $A c k r 2^{-I-}$ mice displayed increased serum CCL2 levels and higher numbers of circulating inflammatory Ly6C ${ }^{\text {high }}$ monocytes at day 14 after UUO (Supplemental Figure S5). Thus, in contrast to progressive renal fibrosis after IRI, and despite similar systemic effects, Ackr2 deficiency did not accelerate renal leukocyte accumulation, inflammation, and tubulointerstitial fibrosis in the UUO model of CKD, which is characterized by severe tubular injury and rapid fibrotic remodeling.

Ackr2 Deficiency Aggravates Renal Injury, Inflammation, and Interstitial Fibrosis after Aristolochic Acid-Induced Nephropathy

To clarify whether anti-inflammatory and antifibrotic functions of ACKR2 are specific to chronic IRI, or can be extended to other forms of AKI that lead to CKD, aristolochic acid-induced nephropathy was induced in wild-type and $A c k r 2^{-/-}$mice. After the aristolochic acid-induced tubulotoxic injury, wild-type mice developed progressive renal failure accompanied by leukocyte infiltration and inflammation (Figure 8). Despite comparable initial injury, $A c k r 2$ deficiency significantly aggravated renal functional impairment and tubular injury in the chronic phase of the model, which was associated with increased renal leukocyte accumulation and the expression of inflammatory mediators (Figure 8). More important, fibrotic remodeling 
of injured kidneys was more severe in $A c k r 2^{-/-}$mice, as revealed by increased renal expression of extracellular matrix molecules and fibrosis markers and more extensive accumulation of Masson trichrome-stained interstitial matrix and $\alpha-\mathrm{SMA}^{+}$myofibroblasts (Figure 9). These data support the contention that ACKR2 plays an important role in limiting fibrotic remodeling and progression to CKD after various forms of $\mathrm{AKI}$, including ischemic and tubulotoxic injury.

\section{Discussion}

After AKI, persistent inflammatory injury instead of a resolution of inflammation promotes nephron loss, fibrotic remodeling, and progression to CKD. Therefore, factors controlling local inflammatory responses are essential for tubular repair and functional recovery after acute renal insults, including IRI. ${ }^{3,34,35}$ ACKR2 promotes resolution of inflammation by chemokine clearance from inflamed sites, ${ }^{7,36}$ and an anti-inflammatory role of ACKR2 has been demonstrated in various disease models. ${ }^{12-15}$ Herein, it was shown that ACKR2 also limits inflammation after renal IRI. In wild-type mice, renal ACKR2 expression was significantly induced after IRI and was localized to endothelial cells of the tubulointerstitium. Previously, increased CCL2 levels have been noticed in the supernatants of $A c k r 2$-deficient tubulointerstitial tissue but not glomeruli on stimulation with tumor necrosis factor- $\alpha,{ }^{27}$ which contributes to renal damage after IRI. ${ }^{37-39}$ These observations are consistent with a reduced ability of $A c k r 2^{-/-}$tissue to locally scavenge and degrade chemokines, and with the expression of ACKR2 on lymphatic endothelial cells, ${ }^{11}$ which in the kidney are present in the tubulointerstitium, but not in glomeruli. In vivo, increased intrarenal chemokine levels in $A c k r 2^{-1-}$ mice were associated with more severe tubular injury and enhanced accumulation of mononuclear phagocytes in postischemic $A c k r 2^{-/}$kidneys at early (day 5 ) but more prominently at late (week 5) time points after IRI. Studies in other disease models have reported similar findings of increased leukocyte numbers and tissue damage in affected organs of $A c k r 2^{-/-}$mice. ${ }^{13,20,40}$ Moreover, $A c k r 2$ deficiency resulted in more severe inflammation in postischemic kidneys, as revealed by increased renal expression of proinflammatory chemokines and M1 macrophage markers. CCL2 promotes infiltration of $\mathrm{CD}_{11} \mathrm{~b}^{+}$Ly6 $\mathrm{C}^{\text {high }}$ inflammatory monocytes into postischemic kidneys, which is dependent on the CCL2 receptor CCR2. ${ }^{32}$ Along this line, a significant increase in CCR2expressing $\mathrm{CD} 11 \mathrm{~b}^{+}$Ly6C $\mathrm{C}^{\text {high }}$ macrophages was observed in $A c k r 2^{-/-}$kidneys 5 weeks after IRI. This suggests that increased tubulointerstitial CCL2 levels in postischemic $A c k r 2^{-/-}$kidneys may enhance the CCL2/CCR2-dependent recruitment of inflammatory macrophages during the regeneration phase after IRI. Moreover, Ackr2 deficiency increased systemic inflammation that was characterized by high CCL2 levels and increased levels of neutrophils and $\mathrm{CD}_{11 \mathrm{~b}^{+}}$Ly6 $\mathrm{C}^{\text {high }}$ inflammatory monocytes in the peripheral circulation. This may additionally enhance early and persistent inflammatory leukocyte infiltrates into postischemic kidneys of $A c k r 2^{-/-}$mice. Thus, when resolution of renal inflammation is needed to help shift the balance from ongoing inflammatory injury to regeneration, $A c k r 2$ deficiency promotes persistent inflammation with associated aggravated tubular injury in postischemic kidneys, which drives AKI toward CKD.

The development of CKD after AKI is characterized not only by tubular loss but also interstitial fibrosis. ${ }^{5,6} A c k r 2$ deficiency promoted fibrosis in postischemic kidneys. Five weeks after IRI, an increase in mRNA expression levels was found for M1 and M2 macrophage markers in Ackr2 ${ }^{-1-}$ kidneys. Renal phagocytes with an M2 phenotype mediate tissue repair and also promote matrix deposition and fibrotic remodeling. ${ }^{28,41}$ Consistently, postischemic kidneys from $A c k r 2^{-/-}$mice displayed a significantly enhanced expression of extracellular matrix-associated molecules and fibroblast markers, as well as increased numbers of $\alpha$ $\mathrm{SMA}^{+}$myofibroblasts within the tubulointerstitium. In addition, bone marrow-derived fibrogenic cells, such as $\mathrm{CD} 5^{+} \mathrm{CD}_{11 \mathrm{~b}^{+}}$collagen $1^{+}$fibrocytes, are thought to contribute to fibrotic progression after renal IRI. ${ }^{42,43}$ Fibrocytes express CCR2. ${ }^{26}$ Therefore, increased levels of the CCR2 ligand CCL2 in Ackr2 $2^{-/-}$kidneys may enhance renal fibrocyte recruitment after IRI. Using flow cytometry, a significant increase in fibrocytes in postischemic Ackr2 ${ }^{-/}$ kidneys 5 weeks after IRI was confirmed. Interestingly, an activated CCL2/CCR2 axis was also found to enhance fibrocyte recruitment in a model of IL-10-induced lung fibrosis. ${ }^{44}$ Thus, in addition to promoting persistent inflammatory injury, $A c k r 2$ deficiency may directly contribute to fibrotic tissue remodeling after renal IRI by facilitating CCL2-dependent fibrocyte recruitment into postischemic kidneys.

Prominent tubulointerstitial expression of CCL2 and concomitant infiltration of CCR2 ${ }^{+}$mononuclear leukocytes and fibrocytes also occur during progressive tubular injury in UUO kidneys after complete ureter ligation. ${ }^{26,45-47}$ This suggested that a potential aggravation of interstitial inflammation and fibrosis could occur in obstructed $A c k r 2^{-/-}$kidneys. However, Ackr2 deficiency was not found to significantly affect tubular injury, leukocyte accumulation, inflammation, or progressive fibrosis in UUO kidneys, despite increased serum CCL2 levels and circulating inflammatory monocytes in $A c k r 2^{-1-}$ mice at day 14 after UUO. This suggests that a lack of ACKR2dependent chemokine scavenging does not influence the severe inflammation and tubular injury seen in UUO kidneys. Because permanent ureter ligation leads to progressive damage of obstructed kidneys, the model lacks a repair phase after the AKI event, in which ACKR2 activity could limit ongoing inflammation and facilitate tissue regeneration. 
To further explore the potential function of ACKR2 in limiting the progression toward CKD after AKI, aristolochic acid-induced nephropathy was analyzed as an additional model of AKI-induced CKD, in which a regenerative phase follows the initial renal injury. Similar to postischemic kidneys, $A c k r 2$ deficiency resulted in more severe renal damage, inflammation, and fibrotic remodeling in this model. Comparable anti-inflammatory and antifibrotic effects of ACKR2 were recently reported in mice with immune complex glomerulonephritis that was induced by injection of nephrotoxic serum. ${ }^{27}$ Taken together, these data suggest an important general role for ACKR2 in limiting ongoing inflammation and fibrotic tissue remodeling in the kidney after an episode of renal injury. However, a recent study in diabetic OVE mice found that $A c k r 2$ deficiency resulted in renal protection, reduced leukocyte infiltration, and decreased renal fibrosis at 6 months. ${ }^{48}$ Reasons for these discrepant results are unclear, but may again lie in the progressive nature of diabetic kidney injury. Similar to ureter ligation in the UUO model, persisting hyperglycemia leads to ongoing tissue damage without subsequent recovery periods. Moreover, by diversely affecting chemokine-mediated accumulation of immunosuppressive versus proinflammatory leukocyte subsets in chronic disease, ACKR2 may, depending on disease type and chronicity, mediate complex and not solely antiinflammatory effects. ${ }^{19}$

In summary, our findings identify ACKR2 as an endogenous regulator limiting tubular injury, persistent inflammation, and fibrotic remodeling after renal IRI and tubulotoxic damage. This study suggests that ACKR2mediated control of local inflammatory responses facilitates tubular repair and recovery after episodes of acute renal injury. Therefore, ACKR2 may be a suitable target for innovative therapeutic approaches to inhibit progression to CKD after AKI.

\section{Acknowledgments}

We thank Dan Draganovici and Jana Mandelbaum for excellent technical assistance.

\section{Supplemental Data}

Supplemental material for this article can be found at https://doi.org/10.1016/j.ajpath.2018.09.016.

\section{References}

1. Chawla LS, Kimmel PL: Acute kidney injury and chronic kidney disease: an integrated clinical syndrome. Kidney Int 2012, 82: $516-524$

2. Rabb H, Griffin MD, McKay DB, Swaminathan S, Pickkers P, Rosner MH, Kellum JA, Ronco C: Acute dialysis quality initiative consensus XWG: inflammation in AKI: current understanding, key questions, and knowledge gaps. J Am Soc Nephrol 2016, 27 : $371-379$

3. Anders HJ, Vielhauer V, Schlöndorff D: Chemokines and chemokine receptors are involved in the resolution or progression of renal disease. Kidney Int 2003, 63:401-415

4. Bonventre JV, Yang L: Cellular pathophysiology of ischemic acute kidney injury. J Clin Invest 2011, 121:4210-4221

5. Wynn TA, Ramalingam TR: Mechanisms of fibrosis: therapeutic translation for fibrotic disease. Nat Med 2012, 18:1028-1040

6. Lovisa S, Zeisberg M, Kalluri R: Partial epithelial-to-mesenchymal transition and other new mechanisms of kidney fibrosis. Trends Endocrinol Metab 2016, 27:681-695

7. Graham GJ, Locati M: Regulation of the immune and inflammatory responses by the "atypical" chemokine receptor D6. J Pathol 2013, 229:168-175

8. Bonavita O, Mollica Poeta V, Setten E, Massara M, Bonecchi R ACKR2: an atypical chemokine receptor regulating lymphatic biology. Front Immunol 2016, 7:691

9. Nibbs RJ, Wylie SM, Yang J, Landau NR, Graham GJ: Cloning and characterization of a novel promiscuous human $\beta$-chemokine receptor D6. J Biol Chem 1997, 272:32078-32083

10. Nibbs RJ, Wylie SM, Pragnell IB, Graham GJ: Cloning and characterization of a novel murine $\beta$ chemokine receptor, D6: comparison to three other related macrophage inflammatory protein- $1 \alpha$ receptors, CCR-1, CCR-3, and CCR-5. J Biol Chem 1997, 272:12495-12504

11. Nibbs RJ, Kriehuber E, Ponath PD, Parent D, Qin S, Campbell JD, Henderson A, Kerjaschki D, Maurer D, Graham GJ, Rot A: The $\beta$ chemokine receptor D6 is expressed by lymphatic endothelium and a subset of vascular tumors. Am J Pathol 2001, 158:867-877

12. Martinez de la Torre Y, Locati M, Buracchi C, Dupor J, Cook DN Bonecchi R, Nebuloni M, Rukavina D, Vago L, Vecchi A, Lira SA, Mantovani A: Increased inflammation in mice deficient for the chemokine decoy receptor D6. Eur J Immunol 2005, 35:1342-1346

13. Cochain C, Auvynet C, Poupel L, Vilar J, Dumeau E, Richart A, Recalde A, Zouggari Y, Yin KY, Bruneval P, Renault G, Marchiol C, Bonnin P, Levy B, Bonecchi R, Locati M, Combadiere C, Silvestre JS: The chemokine decoy receptor D6 prevents excessive inflammation and adverse ventricular remodeling after myocardial infarction. Arterioscler Thromb Vasc Biol 2012, 32:2206-2213

14. Di Liberto D, Locati M, Caccamo N, Vecchi A, Meraviglia S, Salerno A Sireci G, Nebuloni M, Caceres N, Cardona PJ, Dieli F, Mantovani A: Role of the chemokine decoy receptor D6 in balancing inflammation, immune activation, and antimicrobial resistance in Mycobacterium tuberculosis infection. J Exp Med 2008, 205:2075-2084

15. Berres ML, Trautwein C, Zaldivar MM, Schmitz P, Pauels K, Lira SA Tacke F, Wasmuth HE: The chemokine scavenging receptor D6 limits acute toxic liver injury in vivo. Biol Chem 2009, 390:1039-1045

16. Lee KM, McKimmie CS, Gilchrist DS, Pallas KJ, Nibbs RJ, Garside P, McDonald V, Jenkins C, Ransohoff R, Liu L, Milling S, Cerovic V, Graham GJ: D6 facilitates cellular migration and fluid flow to lymph nodes by suppressing lymphatic congestion. Blood 2011, 118: $6220-6229$

17. McKimmie CS, Singh MD, Hewit K, Lopez-Franco O, Le Brocq M, Rose-John S, Lee KM, Baker AH, Wheat R, Blackbourn DJ, Nibbs RJ, Graham GJ: An analysis of the function and expression of D6 on lymphatic endothelial cells. Blood 2013, 121:3768-3777

18. Liu L, Graham GJ, Damodaran A, Hu T, Lira SA, Sasse M, CanastoChibuque C, Cook DN, Ransohoff RM: Cutting edge: the silent chemokine receptor D6 is required for generating $\mathrm{T}$ cell responses that mediate experimental autoimmune encephalomyelitis. J Immunol 2006, 177:17-21

19. Savino B, Castor MG, Caronni N, Sarukhan A, Anselmo A, Buracchi C, Benvenuti F, Pinho V, Teixeira MM, Mantovani A, Locati M, Bonecchi R: Control of murine Ly6 $\mathrm{C}^{\text {high }}$ monocyte traffic and immunosuppressive activities by atypical chemokine receptor D6. Blood 2012, 119:5250-5260 
20. Jamieson T, Cook DN, Nibbs RJ, Rot A, Nixon C, McLean P, Alcami A, Lira SA, Wiekowski M, Graham GJ: The chemokine receptor D6 limits the inflammatory response in vivo. Nat Immunol 2005, 6:403-411

21. Anders HJ, Vielhauer V, Frink M, Linde Y, Cohen CD, Blattner SM, Kretzler M, Strutz F, Mack M, Gröne HJ, Onuffer J, Horuk R, Nelson PJ, Schlöndorff D: A chemokine receptor CCR-1 antagonist reduces renal fibrosis after unilateral ureter ligation. J Clin Invest 2002, 109:251-259

22. Vielhauer V, Allam R, Lindenmeyer MT, Cohen CD, Draganovici D, Mandelbaum J, Eltrich N, Nelson PJ, Anders HJ, Pruenster M, Rot A, Schlöndorff D, Segerer S: Efficient renal recruitment of macrophages and $\mathrm{T}$ cells in mice lacking the duffy antigen/receptor for chemokines. Am J Pathol 2009, 175:119-131

23. Huang L, Scarpellini A, Funck M, Verderio EA, Johnson TS: Development of a chronic kidney disease model in C57BL/6 mice with relevance to human pathology. Nephron Extra 2013, 3:12-29

24. Broekema M, Harmsen MC, Koerts JA, Petersen AH, van Luyn MJ, Navis G, Popa ER: Determinants of tubular bone marrow-derived cell engraftment after renal ischemia/reperfusion in rats. Kidney Int 2005, 68:2572-2581

25. Schwarz M, Taubitz A, Eltrich N, Mulay SR, Allam R, Vielhauer V: Analysis of TNF-mediated recruitment and activation of glomerular dendritic cells in mouse kidneys by compartment-specific flow cytometry. Kidney Int 2013, 84:116-129

26. Reich B, Schmidbauer K, Rodriguez Gomez M, Johannes Hermann F, Göbel N, Brühl H, Ketelsen I, Talke Y, Mack M: Fibrocytes develop outside the kidney but contribute to renal fibrosis in a mouse model. Kidney Int 2013, 84:78-89

27. Bideak A, Blaut A, Hoppe JM, Müller MB, Federico G, Eltrich N, Gröne HJ, Locati M, Vielhauer V: The atypical chemokine receptor 2 limits renal inflammation and fibrosis in murine progressive immune complex glomerulonephritis. Kidney Int 2018, 93:826-841

28. Mantovani A, Sica A, Sozzani S, Allavena P, Vecchi A, Locati M: The chemokine system in diverse forms of macrophage activation and polarization. Trends Immunol 2004, 25:677-686

29. Niedermeier M, Reich B, Rodriguez Gomez M, Denzel A, Schmidbauer K, Göbel N, Talke Y, Schweda F, Mack M: CD4 ${ }^{+} \mathrm{T}$ cells control the differentiation of $\mathrm{Gr}^{+}$monocytes into fibrocytes. Proc Natl Acad Sci U S A 2009, 106:17892-17897

30. Serbina NV, Pamer EG: Monocyte emigration from bone marrow during bacterial infection requires signals mediated by chemokine receptor CCR2. Nat Immunol 2006, 7:311-317

31. Tsou CL, Peters W, Si Y, Slaymaker S, Aslanian AM, Weisberg SP, Mack M, Charo IF: Critical roles for CCR2 and MCP-3 in monocyte mobilization from bone marrow and recruitment to inflammatory sites. J Clin Invest 2007, 117:902-909

32. Li L, Huang L, Sung SS, Vergis AL, Rosin DL, Rose CE Jr, Lobo PI, Okusa MD: The chemokine receptors CCR2 and CX3CR1 mediate monocyte/macrophage trafficking in kidney ischemia-reperfusion injury. Kidney Int 2008, 74:1526-1537

33. Eddy AA, Lopez-Guisa JM, Okamura DM, Yamaguchi I: Investigating mechanisms of chronic kidney disease in mouse models. Pediatr Nephrol 2012, 27:1233-1247

34. Yang L, Besschetnova TY, Brooks CR, Shah JV, Bonventre JV: Epithelial cell cycle arrest in G2/M mediates kidney fibrosis after injury. Nat Med 2010, 16:535-543
35. Mulay SR, Thomasova D, Ryu M, Anders HJ: MDM2 (murine double minute-2) links inflammation and tubular cell healing during acute kidney injury in mice. Kidney Int 2012, 81:1199-1211

36. Weber M, Blair E, Simpson CV, O'Hara M, Blackburn PE, Rot A, Graham GJ, Nibbs RJ: The chemokine receptor D6 constitutively traffics to and from the cell surface to internalize and degrade chemokines. Mol Biol Cell 2004, 15:2492-2508

37. Donnahoo KK, Meng X, Ayala A, Cain MP, Harken AH, Meldrum DR: Early kidney TNF- $\alpha$ expression mediates neutrophil infiltration and injury after renal ischemia-reperfusion. Am J Physiol 1999, 277:R922-R929

38. Dong X, Swaminathan S, Bachman LA, Croatt AJ, Nath KA, Griffin MD: Resident dendritic cells are the predominant TNFsecreting cell in early renal ischemia-reperfusion injury. Kidney Int 2007, 71:619-628

39. Choi DE, Jeong JY, Lim BJ, Na KR, Shin YT, Lee KW: Pretreatment with the tumor nerosis factor- $\alpha$ blocker etanercept attenuated ischemiareperfusion renal injury. Transplant Proc 2009, 41:3590-3596

40. Whitehead GS, Wang T, DeGraff LM, Card JW, Lira SA, Graham GJ, Cook DN: The chemokine receptor D6 has opposing effects on allergic inflammation and airway reactivity. Am J Respir Crit Care Med 2007, $175: 243-249$

41. Cao Q, Zheng D, Wang YP, Harris DC: Macrophages and dendritic cells for treating kidney disease. Nephron Exp Nephrol 2011, 117: e47-e52

42. Broekema M, Harmsen MC, van Luyn MJ, Koerts JA, Petersen AH, van Kooten TG, van Goor H, Navis G, Popa ER: Bone marrowderived myofibroblasts contribute to the renal interstitial myofibroblast population and produce procollagen I after ischemia/reperfusion in rats. J Am Soc Nephrol 2007, 18:165-175

43. Jang HS, Kim JI, Han SJ, Park KM: Recruitment and subsequent proliferation of bone marrow-derived cells in the postischemic kidney are important to the progression of fibrosis. Am J Physiol Renal Physiol 2014, 306:F1451-F1461

44. Sun L, Louie MC, Vannella KM, Wilke CA, LeVine AM, Moore BB, Shanley TP: New concepts of IL-10-induced lung fibrosis: fibrocyte recruitment and M2 activation in a CCL2/CCR2 axis. Am J Physiol Lung Cell Mol Physiol 2011, 300:L341-L353

45. Vielhauer V, Anders HJ, Mack M, Cihak J, Strutz F, Stangassinger M, Luckow B, Gröne HJ, Schlöndorff D: Obstructive nephropathy in the mouse: progressive fibrosis correlates with tubulointerstitial chemokine expression and accumulation of CC chemokine receptor 2- and 5positive leukocytes. J Am Soc Nephrol 2001, 12:1173-1187

46. Kitagawa K, Wada T, Furuichi K, Hashimoto H, Ishiwata Y, Asano M, Takeya M, Kuziel WA, Matsushima K, Mukaida N, Yokoyama H: Blockade of CCR2 ameliorates progressive fibrosis in kidney. Am J Pathol 2004, 165:237-246

47. Wada T, Furuichi K, Sakai N, Iwata Y, Kitagawa K, Ishida Y, Kondo T, Hashimoto H, Ishiwata Y, Mukaida N, Tomosugi N, Matsushima K, Egashira K, Yokoyama H: Gene therapy via blockade of monocyte chemoattractant protein-1 for renal fibrosis. J Am Soc Nephrol 2004, 15:940-948

48. Zheng S, Coventry S, Cai L, Powell DW, Jala VR, Haribabu B, Epstein PN: Renal protection by genetic deletion of the atypical chemokine receptor ACKR2 in diabetic OVE mice. J Diabetes Res 2016, 2016:5362506 